\title{
Two Monetary Tools: Interest Rates and Haircuts
}

\author{
Adam Ashcraft, Federal Reserve Bank of New York \\ Nicolae Gârleanu, University of California at Berkeley, NBER, and CEPR \\ Lasse Heje Pedersen, New York University, NBER, and CEPR
}

If it is known that the Bank of England is freely advancing on what in ordinary times is reckoned a good security - on what is then commonly pledged and easily convertible- the alarm of the solvent merchants and bankers will be stayed.

-Walter Bagehot $(1873,198)$

Financial institutions play a key role as credit providers in the economy, and liquidity crises arise when they become credit constrained themselves. In such liquidity crises, financial institutions' ability to borrow against their securities plays a key role, as Bagehot points out. In the private markets, it can become virtually impossible to borrow against certain illiquid securities, and, more broadly, the "haircuts" (also called margin requirements) on many securities increase in crises. ${ }^{1}$ Furthermore, security prices may drop significantly, especially for securities with high haircuts. To alleviate the financial institutions' funding problems, and their repercussions on the real economy, central banks have a number of monetary policy tools available, such as interest rate cuts and lending facilities with low haircuts.

This paper studies the links between haircuts, required returns, and real activity, and evaluates the different monetary policy tools theoretically and empirically. In a production economy with multiple sectors financed by agents facing margin constraints, we show that binding constraints increase required returns and propagate business cycles. The central bank policy of reducing the interest rate decreases the required returns of low-haircut assets but may increase those of high-haircut assets, since it may increase the shadow cost of capital for constrained agents. A reduction in the haircut of an asset unambiguously lowers its required return and can ease the funding constraints on all assets. 
Empirically, we estimate that lowering haircuts through lending facilities significantly decreased the required return during the recent crisis, and we provide unique survey evidence suggesting a strong demand sensitivity to haircuts.

Our model features heterogeneous-risk-aversion agents who are limited to holding positions with total haircuts not exceeding the agents' capital. While this is a single funding constraint, it affects securities differently, depending on their haircuts. This is the key funding constraint for real-world financial institutions; for instance, Bear Stearns, Lehman, and AIG collapsed when they could not meet their margin constraints.

In the model, risk-tolerant agents take leveraged positions in equilibrium, and, as we will see, play a role that resembles that of the realworld financial institutions described above. When these leveraged agents' margin requirements become binding, their shadow cost of capital increases, driving up equilibrium required returns, especially for high-haircut assets, which use more of the now expensive capital. This mechanism lowers investment and output, and leads to persistent effects of i.i.d. (independently and identically distributed) productivity shocks, thus exacerbating business cycle swings, especially in high-haircut sectors. The margin-constraint business cycle is driven by risk-tolerant agents' wealth as the key state variable, which falls whenever asset values and labor income do. The consequences are disproportionately severe for the high-haircut sectors because constrained investors reallocate capital toward assets that can be financed (i.e., leveraged) more easily.

Central banks often fight low real activity by reducing the interest rate to lower the required return on capital. This policy, however, makes leveraged investing more attractive, thus possibly increasing the shadow cost of capital, which in turn may actually increase the required return on high-haircut assets. Low-haircut assets' returns, on the other hand, depend only weakly on the shadow cost of capital-the extreme case is that of an asset with zero haircut, whose required return is driven purely by the interest rate and riskiness, and independent of the state of the constraint-and therefore are brought down by reducing interest rates. Naturally, decreases in required returns are accompanied by increased investment and production, and vice versa.

This observation motivates a natural policy question: What can be done when lowering the interest rate does not help high-haircut sectors (or when the nominal interest rate is already zero)? As Bagehot points out, the central bank can lend against a wide range of securities and, we might add, at a modest yet prudent haircut. We show that if the 
central bank decides to accept a particular security as collateral at a lower haircut than otherwise available, this always lowers its required return. The required returns of other securities either all increase or all decrease, depending on what happens to the shadow cost of capital. The most intuitive case is that the shadow cost of capital decreases due to the new source of funding, thus helping other securities as well, and we show that this happens when the haircut is reduced sufficiently.

Further, the shadow cost of capital decreases if the haircut on enough securities can be lowered. This observation is relevant for the debate about whether central banks should extend their lending facilities to legacy securities or restrict attention to new issues. The Term AssetBacked Securities Loan Facility (TALF) program was initially focused on newly issued securities, since these imply new credit provided to the real economy. Lowering the haircut on these securities helps reduce their required returns but does little to ease the overall funding constraints in the financial sector. The legacy TALF program applied to existing securities and therefore had the potential to alleviate the funding problems more broadly_and flatten the haircut-return curve as a result.

As a final theoretical result, we show that the shadow cost of capital can be reduced through asset purchases or capital injections. Hence, these policy tools also lower required returns and stimulate real activity, but they may be associated with significant costs and risks.

Empirically, we find that central bank provided loans at modest haircuts can be a powerful tool for lowering yields and stimulating economic activity. We arrive at this conclusion by studying the introduction of the legacy TALF that provided loans with lower haircuts and longer maturity than otherwise available. Yields went down significantly when the TALF program was announced, increased when Standard and Poor's (S\&P) changed its ratings methodology in a way that would make a number of securities ineligible for TALF, and finally went down again, and further than before, when TALF was implemented. We note that the yield of both TALF eligible and ineligible securities reacted to the news, consistent with the idea that the common shadow cost of capital was affected.

While suggestive, this string of yield reactions does not provide conclusive evidence, since so many other things went on at the same time. We use two approaches to isolate the effect of TALF: (1) we study evidence from a survey conducted in March 2009 (before the legacy TALF was introduced) asking market participants the prices they would bid for certain securities without TALF, with access to high-haircut term funding, and with access to low-haircut term funding; and (2) we study the reaction of market prices, adjusting for non-TALF effects by 
considering the price response to unpredictable bond rejections from the TALF program.

The survey indicated that participants would pay $6 \%$ more for a super senior CMBS (commercial mortgage-backed securities) bond if they had access to a 3-year loan with a high haircut than they would pay if they had no access to term leverage. The bid price was higher for lower haircuts and longer maturities, reaching $50 \%$ above the no-TALF bid for the longest term loan with a low haircut. The significance of the effect is also apparent in terms of yields: participants required a $15 \%$ yield without access to term leverage (which was the yield prevailing in the market), but their required bond yields dropped to $12 \%$ with access to 3 -year loans with a low haircut (similar to what was actually implemented in TALF), and to $9.5 \%$ for 5 -year loans. Hence, according to this survey, low-haircut term leverage similar to TALF had the potential to lower yields by $3 \%-5 \%$ for super senior bonds.

These results are evidence of significant demand sensitivity to haircuts. To make sure that the higher bid reflects the value of financing, not the value of being able to default on the loan, we focus on super senior CMBS, as these are the safest bonds. The participants in the survey were asked to estimate the losses on the pool in a stress scenario, and, even in the stress scenario, the estimated losses on the pool imply no losses on the safest super senior tranches.

The survey evidence is corroborated by transaction-price data showing the effect of TALF on actual bond yields, controlling for other effects. Indeed, we find a statistically significant rise in the yield spread of bonds that are unexpectedly rejected from the TALF program by the Fed, over and above the yield change of other bonds in the same security class during the same week. In other words, the required return rises for bonds that fail to benefit from TALF's lower haircuts. As further evidence consistent with the model, we find that this rise in yield is greater during the early part of the program (July-September 2009), when capital constraints were more binding, than in the later period (October 2009-March 2010). During the early period, we estimate that the TALF rejection led to an immediate 80 bps rise in yield, with the effect eventually falling to $40 \mathrm{bps}$.

The effect of lowering haircuts during crises can likely far exceed the estimated $40 \mathrm{bps}$ long-term effect, for a couple of reasons. First, the economy and capital constraints had already improved substantially during this early legacy TALF period relative to the height of the crisis (e.g., March 2009, when the survey was conducted). Thus, the haircut effect during the height of the crisis would likely have been significantly larger. Second, we are only measuring the effect of a bond's haircut on its own 
yield, not that of the lending program on the liquidity in the system more broadly. In the language of our theory, we estimate only the effect of moving a bond along the haircut-return curve, not the flattening of the curve itself.

Our overall evidence suggests that the haircut tool is a powerful one, consistent with our model. To put the magnitude in perspective, recall that the Fed lowered the Fed funds rate from 5.25\% in early 2007 all the way to the zero lower bound $(0 \%-0.25 \%)$, a $5 \%$ reduction. Since we estimate that the haircut tool implemented with a program such as TALF can lower yields by well in excess of $0.40 \%$, perhaps up to $3 \%-5 \%$ as our survey suggests, its effectiveness appears economically significant.

The estimated economic magnitude can be understood in the context of the model as follows: lowering the haircut by $80 \%$ lowers the required return by approximately $10 \% \times 80 \% \times 40 \%=3 \%$ if the shadow cost of capital was around $10 \%$ for the $40 \%$ of risk-bearing capacity that was constrained during the crisis. With standard production functions, this leads to large effects on investment, capital, and output in the affected sectors.

Our paper is related to several large literatures. Borrowing constraints of entrepreneurs and firms affect business cycles and collateral values (Bernanke and Gertler 1989; Detemple and Murthy 1997; Geanakoplos 1997, 2003; Kiyotaki and Moore 1997; Bernanke, Gertler, and Gilchrist 1998; Caballero and Krishnamurthy 2001; Coen-Pirani 2005; Lustig and Van Nieuwerburgh 2005; Fostel and Geanakoplos 2008). ${ }^{2}$

Rather than focusing on borrowers' balance sheet effects (or creditdemand frictions), we consider the lending channel (or credit-supply frictions), as Holmström and Tirole (1997), Repullo and Suarez (2000), and Ashcraft (2005) have. The impact on the macroeconomy of financial frictions has been further studied recently by Kiyotaki and Moore (2008), Adrian, Moench, and Shin (2009), Cúrdia and Woodford (2009), Gertler and Karadi (2009), Gertler and Kiyotaki (2009), Reis (2009), and Adrian and Shin (2010). Also, Lorenzoni (2008) shows that there can be inefficient credit booms due to fire-sale externalities with credit constraints.

Our asset-pricing implications are related to Hindy (1995), Cuoco (1997), Aiyagari and Gertler (1999), and especially Gârleanu and Pedersen (forthcoming). Required returns are also increased by transaction costs and market-liquidity risk (Amihud and Mendelson 1986; Longstaff 2004; Acharya and Pedersen 2005; Duffie, Gârleanu, and Pedersen 2005, 2007; Mitchell, Pedersen, and Pulvino 2007; He and Krishnamurthy 2008). Market liquidity interacts with margin requirements as shown by Brunnermeier and Pedersen (2009), who also explain why margin 
requirements tend to increase during crises because of liquidity spirals, a phenomenon documented empirically by Adrian and Shin (2008) and Gorton and Metrick (2009a, 2009b).

We complement the literature by generating cross-sectional predictions in a multisector model with credit supply frictions due to margin constraints, by showing how interest rate cuts may be ineffective for high-haircut assets during crises, and by evaluating the effect of another monetary tool-haircuts-theoretically and empirically.

Haircuts play a central role in the paper. One may wonder, however, whether this institutional feature is of passing importance. To the contrary, we would argue that loans secured by collateral with a haircut have played an important role in facilitating economic activity for thousands of years. For instance, the first written compendium of Judaism's Oral Law, the Mishnah, states: "One lends money with a mortgage on land which is worth more than the value of the loan. The lender says to the borrower, 'If you do not repay the loan within three years, this land is mine'" (Mishnah Bava Metzia 5:3, circa 200 AD). ${ }^{3}$

The rest of the paper is organized as follows. Section I lays out the model, Section II derives the economic dynamics and effects of haircuts and interest rate cuts, Section III presents the empirical evidence, and Section IV concludes.

\section{Model}

We consider a simple overlapping-generations (OLG) economy in which firms and agents interact at times $\{\ldots,-1,0,1,2, \ldots\}$. At each time $t, J$ new young (representative) firms are started, and there are $J$ old firms that were started during the previous period $t-1$. Old firm $j$ produces output $Y_{t}^{j}$ depending on its capital $K_{t}^{j}$, labor use $L_{t}^{j}$, and productivity $A_{t}^{j}$, which is a random variable. The output is

$$
Y_{t}^{j}=A_{t}^{j} F\left(K_{t}^{j}, L_{t}^{j}\right),
$$

where $F\left(K_{t}^{j}, L_{t}^{j}\right)=\left(K_{t}^{j}\right)^{\alpha}\left(L_{t}^{j}\right)^{\beta}$ is a Cobb-Douglas production function with $\alpha+\beta \leq 1$. The productivity shocks $A_{t}^{j}$ have mean $\bar{A}^{j}$ and variancecovariance matrix $\Sigma_{A}$, assumed invertible. Each type of firm uses its own specialized labor with wage $w_{t}^{j}$. Given the wage, firm $j$ chooses its labor demand to maximize its profit $\bar{P}$ :

$$
\bar{P}\left(K_{t}^{j}, A_{t}^{j}, w_{t}^{j}\right)=\max _{L_{t}^{j}} A_{t}^{j} F\left(K_{t}^{j}, L_{t}^{j}\right)-w_{t}^{j} L_{t}^{j} .
$$


Each young firm invests $I_{t}^{j}$ units of output goods, which become as many units of capital the following period: $K_{t+1}^{j}=I_{t}^{j}$. Capital cannot be redeployed once productivity shocks are realized-in effect, it is specific to a type of firm (and depreciates fully each period as in Bernanke and Gertler 1989). ${ }^{4}$

The firm chooses investment to maximize its present value, which is computed using the pricing kernel $\xi_{t+1}:{ }^{5}$

$$
\max _{I_{t}^{j}} E_{t}\left[\xi_{t+1} \bar{P}\left(I_{t}^{j}, A_{t+1}^{j}, w_{t+1}^{j}\right)\right]-I_{t}^{j} .
$$

Each young firm $j$ issues shares in supply $\theta^{j}$, which we normalize to $\theta^{j}=1$. These shares represent a claim to the firm's profit $\bar{P}_{t+1}^{j}$ next period, $t+1$. The shares are issued at a price of $P_{t}^{j}=E_{t}\left[\xi_{t+1} \bar{P}\left(I_{t}^{j}, A_{t+1}^{j}, w_{t+1}^{j}\right)\right]$. (Note that we use the notation $P_{t}^{j}$ for the price of a young firm at time $t$ and $\bar{P}_{t+1}^{j}$ for the price of the same firm when old.) The firm uses the proceeds from the sale to invest the $I_{t}^{j}$ units of capital. The balance $P_{t}^{j}-I_{t}^{j}$ (which we show to always be nonnegative) represents a profit to the initial owners of the technology.

Each time period, young agents are born who live two periods. Hence, at any time, the economy is populated by young and old agents. Agents differ in their risk aversion; in particular, $a$ agents have a high risk aversion, $\gamma^{a}$, while $b$ agents have a lower risk aversion, $\gamma^{b}$.

All agents are endowed with a fixed number of units of labor for each technology and part of the technology for new firms. Specifically, a young agent (or "family") of type $n \in\{a, b\}$ inelastically supplies $\eta^{n}$ units of labor to each type of firm, where the total supply of labor is normalized to one, $\eta^{a}+\eta^{b}=1$, and owns a fraction $\omega^{n}$ of each of the young firms. At time $t$, a young agent $n \in\{a, b\}$ therefore has a wealth $W_{t}^{n}$ that is the sum of his labor income and the value of his endowment in technologies,

$$
W_{t}^{n}=\sum_{j} w_{t}^{j} \eta^{n}+\sum_{j}\left(P_{t}^{j}-I_{t}^{j}\right) \omega^{n} .
$$

Agents have access to a linear (risk-free) saving technology with net rate of return $r^{f}$ and choose how many shares $\theta$ to buy in each young firm. Depending on an agent's portfolio choice, his wealth evolves according to

$$
W_{t+1}=W_{t}\left(1+r^{f}\right)+\theta^{\top}\left[\bar{P}_{t+1}-P_{t}\left(1+r^{f}\right)\right] .
$$

Shares in asset $j$ are subject to a haircut or margin requirement $m_{t}^{j}$, which limits the amount that can be borrowed using one share of asset $j$ as a collateral to $P^{j}\left(1-m_{t}^{j}\right)$. We can think of haircuts/margin 
requirements as exogenous or as set as in Geanakoplos (2003). Hence, each agent must use capital to buy assets and is subject to the margin requirement

$$
\sum_{j} m_{t}^{j}\left|\theta^{j}\right| P_{t}^{j} \leq W_{t}^{n}
$$

The agents derive utility from consumption when old and seek to maximize their expected quadratic utility: ${ }^{6}$

$$
\max _{\theta} E_{t}\left(W_{t+1}\right)-\frac{\gamma^{n}}{2} \operatorname{Var}_{t}\left(W_{t+1}\right) .
$$

An equilibrium is a collection of processes for wages $w_{t}$, investments $I_{t}$, stock prices $P_{t}$, and pricing kernels $\xi_{t}$ so that markets clear.

\section{A. Haircuts, Credit Supply, and the Required Return}

To solve for the equilibrium, we first take the firms' investments as given and solve for the agents' optimal portfolio choice and the equilibrium required return. Agent $n^{\prime}$ s portfolio choice problem can be stated as

$$
\max _{\theta} W_{t}\left(1+r^{f}\right)+\theta^{\top}\left[E_{t}\left(\bar{P}_{t+1}\right)-P_{t}\left(1+r^{f}\right)\right]-\frac{\gamma^{n}}{2} \theta^{\top} \Sigma_{t} \theta
$$

where the variance-covariance matrix $\Sigma_{t}=\operatorname{Var}_{t}\left(\bar{P}_{t+1}\right)$ is invertible in equilibrium (as shown by eq. [26] below). The first-order condition is

$$
0=E_{t}\left(\bar{P}_{t+1}\right)-P_{t}\left(1+r^{f}\right)-\gamma^{n} \Sigma_{t} \theta-\psi_{t}^{n} D\left(m_{t}\right) P_{t},
$$

where $\psi_{t}^{n}$ is a Lagrange multiplier for the margin constraint, ${ }^{7}$ and $D(\cdot)$ makes a vector into a diagonal matrix. ${ }^{8}$

Hence, the optimal portfolio is

$$
\theta_{t}^{n}=\frac{1}{\gamma^{n}} \Sigma_{t}^{-1}\left[E_{t}\left(\bar{P}_{t+1}\right)-P_{t}\left(1+r^{f}\right)-\psi_{t}^{n} D\left(m_{t}\right) P_{t}\right] .
$$

We assume that we are in the natural case in which the risk-averse agent is unleveraged and therefore has a zero Lagrange multiplier; that is, $\psi^{a}=0$. (This outcome arises naturally with endogenous interest rates; see Gârleanu and Pedersen [forthcoming].) Let $\psi=\psi^{b}$. The marketclearing condition, namely

$$
\bar{\theta}=\theta_{t}^{a}+\theta_{t}^{b}
$$


then implies that

$$
\bar{\theta}=\frac{1}{\gamma} \Sigma_{t}^{-1}\left[E_{t}\left(\bar{P}_{t+1}\right)-P_{t}\left(1+r^{f}\right)\right]-\psi_{t} \frac{1}{\gamma^{b}} \Sigma_{t}^{-1} D\left(m_{t}\right) P_{t},
$$

where we use the notation $\gamma$ as the representative agent's risk aversion,

$$
\frac{1}{\gamma}=\frac{1}{\gamma^{a}}+\frac{1}{\gamma^{b}}
$$

Letting $x=\gamma / \gamma^{b}$, these calculations yield the equilibrium price

$$
P_{t}=D\left(1+r^{f}+\psi_{t} x m_{t}\right)^{-1}\left[E_{t}\left(\bar{P}_{t+1}\right)-\gamma \Sigma \bar{\theta}\right] .
$$

Prices can be translated into returns $r_{t+1}^{j}=\bar{P}_{t+1}^{j} / P_{t}^{j}-1$, giving rise to a modified capital asset pricing model (CAPM). To state such a result, we let $r_{t+1}^{\mathrm{mkt}}=q_{t}^{\top} r_{t+1}$ be the market return, where $q_{t}^{i}=\left(\sum_{j} \theta^{j} P_{t}^{j}\right)^{-1} \theta^{i} P_{t}^{i}$ is the market capitalization weight of asset $i$, and define the market beta in the usual way; that is, $\beta_{t}^{j}=\operatorname{Cov}_{t}\left(r_{t+1}^{j}, r_{t+1}^{\mathrm{mkt}}\right) / \operatorname{Var}_{t}\left(r_{t+1}^{\mathrm{mkt}}\right)$.

Proposition 1 (Margin CAPM). The required return on security $j$ depends on its market beta and its margin requirement:

$$
E_{t}\left(r_{t+1}^{j}\right)-r^{f}=\lambda_{t} \beta_{t}^{j}+m_{t}^{j} \psi_{t} x
$$

where the market risk premium is $\lambda_{t}=E_{t}\left(r_{t+1}^{\mathrm{mkt}}\right)-r^{f}-\left(\sum_{j} m_{t}^{j} q_{t}^{j}\right) \psi_{t} x, m_{t}^{j}$ is the margin requirement on asset $j$, and $\psi_{t}$ is the shadow cost of agent $b$ 's margin constraint.

The positive relation between the required return and beta is a central principle in finance (called the security market line). With margin constraints, the required return also depends on the margin requirement when constraints are binding, since the risk-tolerant agents cannot hold as many securities as they would otherwise. It is important to note that the effect of the constraint differs in the cross section of assets: assets that have high haircuts/margins use a lot of the investors' capital and, therefore, are associated with higher required returns.

Figure 1 illustrates graphically the dependence of the required return on haircuts (the "haircut-return line") when the constraint is slack, as well as when it binds. In the former case, the haircut levels do not affect the required returns, but when the constraint binds, that is, during crises, the required return increases with the haircut.

In the following sections, we consider a number of other economic properties of the model solved with the same parameters as those this figure is based on. The parameters are as follows. All firms have production 


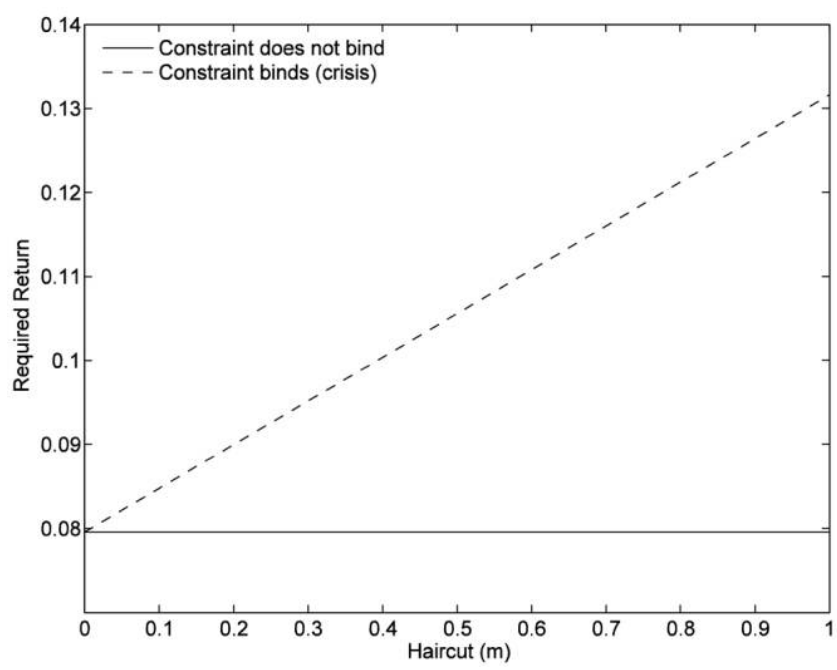

Fig. 1. Required return increases in the margin requirement (or haircut)

function parameters $\alpha=0.3$ and $\beta=1-\alpha=0.7$, and productivity shocks are identically distributed and independent with mean $\bar{A}=3.3$ and standard deviation 0.67 . There are 40 firms with relatively low haircut levels $(m=0.1)$, and 10 more firms with evenly spaced haircuts $m \in\{0.1,0.2, \ldots, 1\}$. We assume that the absolute risk-aversion coefficients of the two agents are $\gamma^{a}=28.5$ and $\gamma^{b}=1.5$. In the "crisis" state, when $b$ is constrained, his wealth is $W^{b}=7.7$, and the "noncrisis" state captures any wealth level $W^{b}>8.1$. Finally, the base-case interest rate is $r^{f}=0.02$.

\section{B. Investment, Income, and Output}

Now we turn to the firm's optimal labor choice and investment. First, when the old firm $j$ optimizes over its labor choice $L_{t}^{j}$, we get the firstorder condition

$$
\beta A_{t}^{j}\left(K_{t}^{j}\right)^{\alpha}\left(L_{t}^{j}\right)^{\beta-1}=w_{t}^{j} .
$$

Given that one unit of labor is supplied inelastically, the equilibrium wage is

$$
w_{t}^{j}=\beta A_{t}^{j}\left(K_{t}^{j}\right)^{\alpha},
$$

since it gives rise to a labor demand of $L_{t}^{j}=1$. It is important to note that a lower capital stock $K$-due to a lower investment in the previous 
period-results in lower wages, a phenomenon that plays an important role in the later analysis.

When young, the firm chooses its optimal investment $I_{t-1}^{j}$ in a competitive environment and hence takes the wage at time $t$ as given. Hence, to solve the young firm's investment problem at time $t-1$, consider first the optimal labor choice when the firm arrives at time $t$ with a capital of $I_{t-1}^{j}$, while wages are set based on capital at time $K_{t}^{j}$ (due to the "other" firms of this type, so not necessarily equal to investment, although $I_{t-1}^{j}=K_{t}^{j}$ in equilibrium):

$$
\begin{aligned}
L_{t}^{j} & =\left[\frac{\beta A_{t}^{j}\left(I_{t-1}^{j}\right)^{\alpha}}{w_{t}^{j}}\right]^{1 /(1-\beta)} \\
& =\left[\frac{\beta A_{t}^{j}\left(I_{t-1}^{j}\right)^{\alpha}}{\beta A_{t}^{j}\left(K_{t}^{j}\right)^{\alpha}}\right]^{1 /(1-\beta)} \\
& =\left(I_{t-1}^{j}\right)^{\alpha /(1-\beta)}\left(K_{t}^{j}\right)^{-[\alpha /(1-\beta)]} .
\end{aligned}
$$

Equation (16) shows that the profit is a fraction $1-\beta$ of the output (due to the Cobb-Douglas production function), so the profit is

$$
(1-\beta) A_{t}^{j}\left(I_{t-1}^{j}\right)^{\alpha}\left(L_{t}^{j}\right)^{\beta}=(1-\beta) A_{t}^{j}\left(I_{t-1}^{j}\right)^{\alpha /(1-\beta)}\left(K_{t}^{j}\right)^{-[\alpha \beta /(1-\beta)]},
$$

which gives the young firm's investment problem as

$$
\max _{I_{t}^{j}}\left\{(1-\beta) E_{t}\left[\xi_{t+1} \bar{A}_{t+1}^{j}\left(I_{t}^{j}\right)^{\alpha_{j} /(1-\beta)}\left(K_{t+1}^{j}\right)^{-\alpha_{j} \beta /(1-\beta)}\right]-I_{t}^{j}\right\} .
$$

The maximum value attained by equation (22) is $P_{t}^{j}-I_{t}^{j}$. The first-order condition is

$$
\frac{\alpha_{j}}{1-\beta}(1-\beta) E_{t}\left[\xi_{t+1} A_{t+1}^{j}\left(I_{t}^{j}\right)^{\alpha_{j} /(1-\beta)-1}\left(K_{t+1}^{j}\right)^{-\alpha_{j} \beta /(1-\beta)}\right]=1,
$$

which implies

$$
P_{t}^{j}=\frac{1-\beta}{\alpha_{i}} I_{t}^{j} \geq I_{t}^{j}
$$

A direct implication of equation (24) is that the firm's initial value (before the shares are issued) is nonnegative. 
Investment decisions determine profits (i.e., the value of old firms), whose moments can be calculated explicitly given that $\bar{P}_{t+1}^{j}=(1-\beta) A_{t+1}^{j}\left(I_{t}^{j}\right)^{\alpha}$ :

$$
\begin{gathered}
E_{t}\left(\bar{P}_{t+1}^{j}\right)=(1-\beta) \bar{A}^{j}\left(I_{t}^{j}\right)^{\alpha}, \\
\Sigma_{t}=(1-\beta)^{2} D\left(I_{t}^{\alpha}\right) \Sigma_{A} D\left(I_{t}^{\alpha}\right) .
\end{gathered}
$$

In turn, these moments determine the required return as discussed in Section I.A. Hence, combining equations (25) and (26) with (14) gives the equation that determines investment:

$$
\left(1+r^{f}+\psi_{t} x m_{t}\right) \frac{1}{\alpha}=D\left(I_{t}^{\alpha-1}\right) E_{t}\left(A_{t+1}\right)-\gamma(1-\beta) D\left(I_{t}^{\alpha-1}\right) \Sigma_{A} I_{t}^{\alpha} .
$$

To see the intuition behind this formula, consider as an example the case when productivity shocks are independent across firms and $\alpha=$ $1 / 2$. Under these assumptions,

$$
\left(I_{t}^{j}\right)^{1 / 2}=\frac{\frac{1}{2} E_{t}\left(A_{t+1}^{j}\right)}{1+r^{f}+\gamma \frac{1-\beta}{2} \operatorname{Var}_{t}\left(A_{t+1}^{j}\right)+\psi_{t} x m_{t}^{j}} .
$$

Naturally, investment increases with the expected productivity $E_{t}\left(A_{t+1}^{j}\right)$ and decreases with productivity $\operatorname{risk} \operatorname{Var}_{t}\left(A_{t+1}^{j}\right)$. Further, investment decreases when the required return is elevated by $\psi$ due to investors' binding margin constraint, especially for assets with high margin requirements $m_{t}^{j}$. This cross-sectional effect is illustrated in figure 2 .

\section{Haircuts, Business Cycles, and Monetary Policy}

We now turn to the equilibrium properties of the economy and the effects of monetary policy. The model is set up to generate no business cycles in the absence of the credit frictions. However, when the margin constraints of the risk-tolerant agents become binding, required returns increase and business cycles arise.

Proposition 2 (Margin Constraint Accelerator). Absent margin constraints, output is independent over time. With margin constraints, output, income, investment, consumption, wages, and required returns are correlated over time, due to the propagation of a productivity shock sufficiently severe to make the risk-tolerant investors' margin requirement bind. 


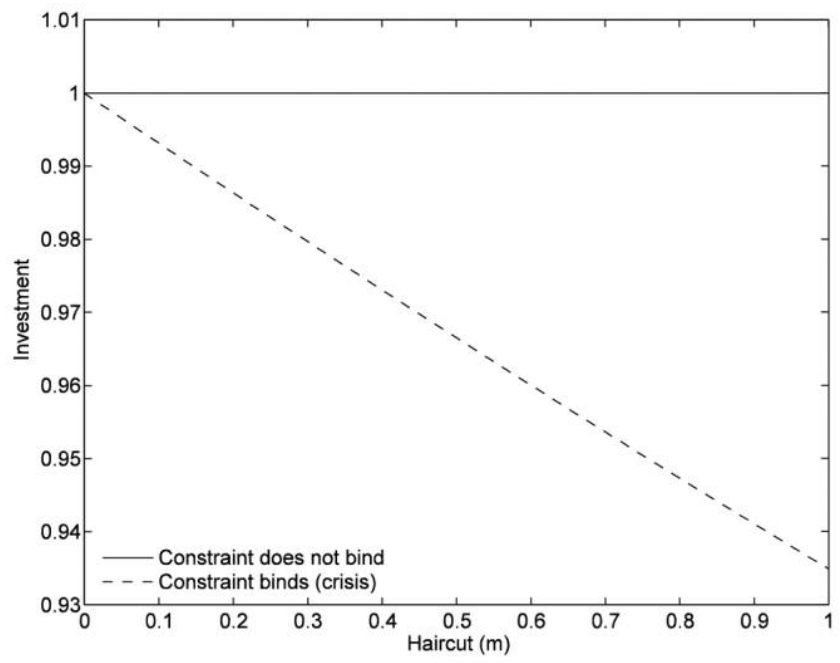

Fig. 2. Less real investment in high-haircut sectors when constraints bind

Margin-constraint-driven business cycles are propagated through the persistent effect on the wealth of the risk-tolerant agents. The basic mechanism is that binding constraints raise the required return, reducing real investment, which reduces the following period's expected output and income, which in turn makes the financing constraint harder to satisfy, and so on. As seen in figure 3, lower real investment reduces labor

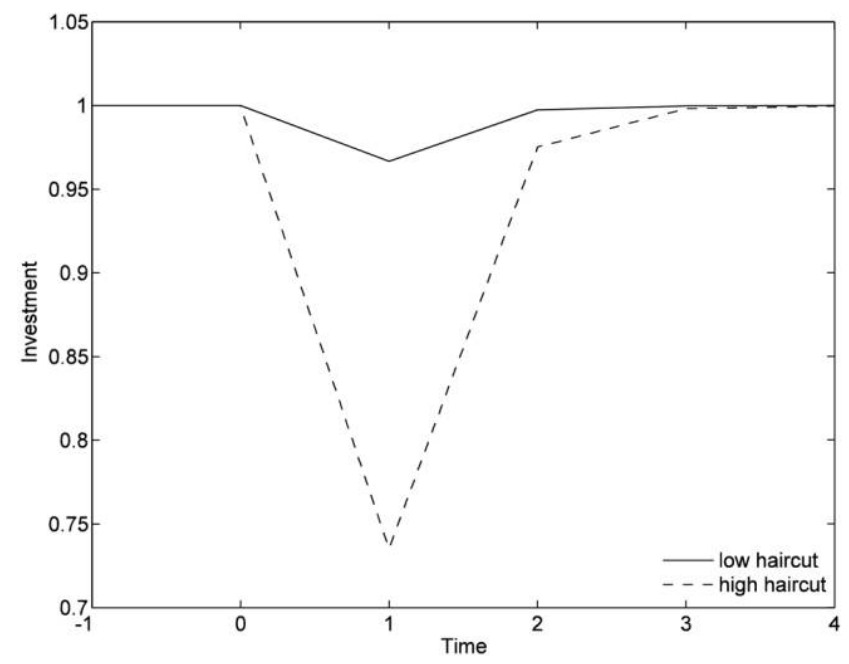

Fig. 3. Real investment following a shock that makes margin requirements bind 
income and the value of technologies, leading to lower real investment in the future, until the risk-tolerant agents are recapitalized.

Next, we consider the effect of a reduction in interest rates. While, in New Keyensian models, monetary policy acts through a reduction in the nominal interest rate, which in turn reduces the real rate because of sticky prices, we take a shortcut and consider the effect of reducing the real rate directly. To concentrate on the margin constraint as the only channel through which different assets interact, we assume throughout this section that productivity shocks are independent in the cross section and that the constraint is binding at time $t$. In the interest of simplicity, we also make the usual assumption $\alpha+\beta=1$.

Proposition 3 (Interest Rate Cuts). If type $a$ agents are sufficiently risk averse, then a cut in the current interest rate increases the shadow cost of capital $\psi_{t}$, increases the required return of high-haircut assets, and lowers the real investment in high-haircut assets. More precisely, there exists a cutoff $\bar{m}_{t}$ with $\min _{i} m_{t}^{i}<\bar{m}_{t}<\max m_{t}^{i}$ such that the required return on asset $i$ increases and the real investment $I^{i}$ decreases if and only if $m_{t}^{i}>\bar{m}_{t} \cdot{ }^{9}$

The effect of an interest rate cut is illustrated in figure 4 . A reduction in the interest rate lowers the required return for assets with low haircuts, but it increases the required return for high-haircut assets. This outcome obtains because risk-tolerant investors' desire for leverage increases with the lower interest rate, elevating the shadow cost of capital. The higher

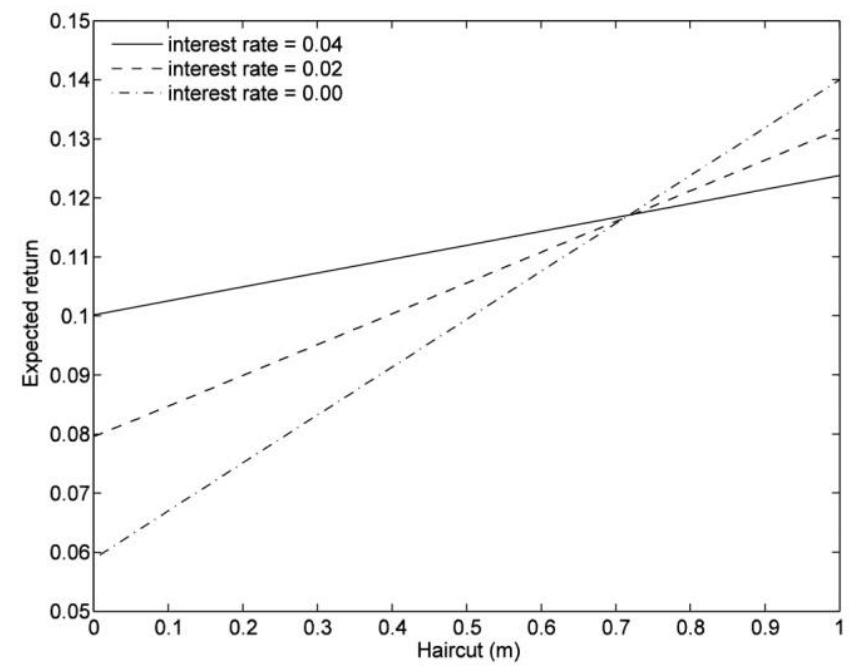

Fig. 4. Interest rate cut: the steepening of the haircut-return relationship 
shadow cost of capital increases the required return, and this effect overwhelms the direct effect of the interest rate cut for high-haircut assets. As a result, the real investment and output decrease in high-margin sectors.

Hence, to increase investment and output in illiquid (i.e., high-haircut) sectors, a central bank needs to either move them down the haircutreturn curve or flatten the entire curve. Said differently, it needs to either (a) target these assets to make them more liquid, or (b) improve the overall liquidity of the system:

Proposition 4 (Haircut Cuts). (a) If the margin requirement on asset $j$ is reduced, then the required return for that asset decreases, and real investment in the asset increases. The real investments in the other assets either all increase or all decrease. (b) The required returns decrease, and real investments increase for all assets if $m_{t}^{j}$ is decreased sufficiently or if the haircuts on sufficiently many assets are decreased by a given fraction.

Figure 5 illustrates the statement of this proposition. The margin constraint on one of the assets is reduced from $m^{j}=0.7$ to $m^{j}=0.5$, which has two effects. First, if asset $j$ is infinitesimal, aggregate quantities remain the same, but the required return on asset $j$ decreases (and investment increases) as it is moved down the haircut-return curve. Second, the reduction in haircut relaxes-this is the typical outcome, although the converse is theoretically possible-the margin constraint of agent $b$, that is, reduces his shadow cost of capital $\psi$, which flattens the haircut-return

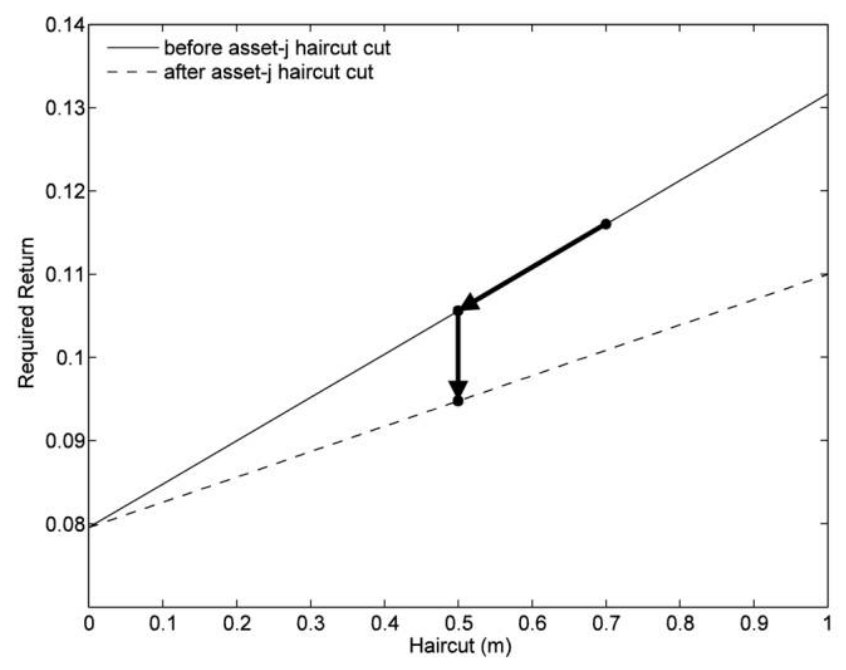

Fig. 5. Haircut cut for one asset 
line, further reducing the required return for asset $j$ as well as that of other assets.

Proposition 4 is the central result that underlies our empirical tests. In the next section, we find that the haircut-return curve indeed flattens when the central bank lending facilities are announced, which is consistent with part $b$, and that a security's yield responds to news about its central bank provided haircut, consistent with part $a$.

It is worth discussing why the central bank can provide loans at lower haircuts than otherwise available in the market. This assumed ability rests on two premises. First, the central bank is special in that it does not have a margin constraint-in contrast, it has a unique access to money that it can lend during crises. Second, while haircuts must be large enough to protect lenders from credit risk, the funding markets can be broken so badly in crises-with market haircuts rising as high as $100 \%$ - and, therefore, the central bank can offer lower haircuts while taking little credit risk.

Just as is the case with productivity shocks covered by proposition 2, the effects of policy intervention are persistent. For instance, reductions in the interest rate or in haircuts change the real investment and therefore future labor income and investment. Indeed, lowering haircuts sufficiently or for sufficiently many assets increases output in both the current and future time periods. These dynamic effects follow intuitively from the previous propositions, so let us instead end this section by considering the effects of capital injections in the institutions whose investment ability is constrained by margin requirements, or purchases of assets in sectors in which the government wants to promote real investment.

Proposition 5 (Capital Injection and Asset Purchases). (a) If agent $b^{\prime}$ s wealth is increased, required returns go down, and real investment increases for all assets. (b) If the government buys shares in asset $i$, then the real investment in that asset increases, and the investments in all other assets all either increase or decrease. If the government purchase is sufficiently large, then all real investments increase.

\section{Haircuts and Prices: The Effect of TALF}

Our theory suggests that the ability to borrow against securities plays an important role in liquidity crises and their resolution. Consistent with this implication, central banks around the world created a number of lending facilities to provide collateralized loans at lower haircuts than otherwise available during a crisis (but often higher than the marketprovided haircut during good times). 
The main lending facility in the United States is the Federal Reserve's Discount Window, which is available only to banks with reserve accounts. The discount window can be used to supply liquidity to banks in times of stress, enabling them to increase lending to the rest of the economy. However, during the crisis of 2007-9, banks' own balance sheet problems impaired this transmission mechanism, and therefore the Fed introduced additional lending facilities, including, for the first time ever, facilities that were available more broadly to nonbanks. The TALF is a good example: it was put in place in 2008 to provide loans against asset-backed securities (ABS) at a haircut, available to any U.S. company or investment fund. The program was motivated by the credit-supply frictions that we model:

New issuance of ABS declined precipitously in September and came to a halt in October. At the same time, interest rate spreads on AAA-rated tranches of ABS soared to levels well outside the range of historical experience, reflecting unusually high risk premiums. The ABS markets historically have funded a substantial share of consumer credit and SBA-guaranteed small business loans. Continued disruption of these markets could significantly limit the availability of credit to households and small businesses and thereby contribute to further weakening of U.S. economic activity. The TALF is designed to increase credit availability and support economic activity by facilitating renewed issuance of consumer and small business ABS at more normal interest rate spreads. (Board of Governors of the Federal Reserve System, press release, November 25, 2008)

The original TALF was directed at lowering the haircut only on newly issued securities, because these securities are related to the new loans provided to the real sector of the economy. This makes it difficult to assess the price effect of the program since these yet-to-be-issued securities were naturally not traded when the program was announced.

TALF was later extended to legacy securities, that is, securities that had been issued before 2009. The extension of TALF to legacy securities sought to reduce the liquidity discount for these securities, improving the balance sheet of financial institutions that held them, and to lower the opportunity cost of making new loans. In the language of our model, the new-issue TALF sought to move newly issued securities down the haircut-return curve, while the legacy TALF sought to flatten the curve itself (proposition 4). We next describe the events surrounding the introduction of the legacy TALF, and then we test empirically its effect. 


\section{A. The Introduction of the Legacy TALF}

The first indication that the Federal Reserve would attempt to support the legacy CMBS market was made in a joint announcement by the Federal Reserve and Treasury on March 19, 2009, suggesting that legacy CMBS with a current AAA rating and legacy RMBS (residential mortgage-backed securities) with an original AAA credit rating were being studied for inclusion in the TALF program. The new-issue TALF program had its first subscription on the same date and provided investors with term nonrecourse leverage against eligible collateral in order to stabilize funding for nonbanks that relied on the term ABS market. The U.S. Treasury also announced details around the securities public-private investment program (PPIP), where the taxpayer would take an equity stake in a joint venture with selected asset managers in order to purchase legacy securities. As illustrated in figure 6, CMBS prices rallied significantly across the capital structure, consistent with a flattening of the haircut return curve (proposition 4). The vertical lines in the graph correspond to this key date as well as four others, summarized below the graph.

On May 19, 2009, the Federal Reserve Bank of New York confirmed that the legacy TALF program would move forward for CMBS and released preliminary terms. In particular, eligible collateral was limited

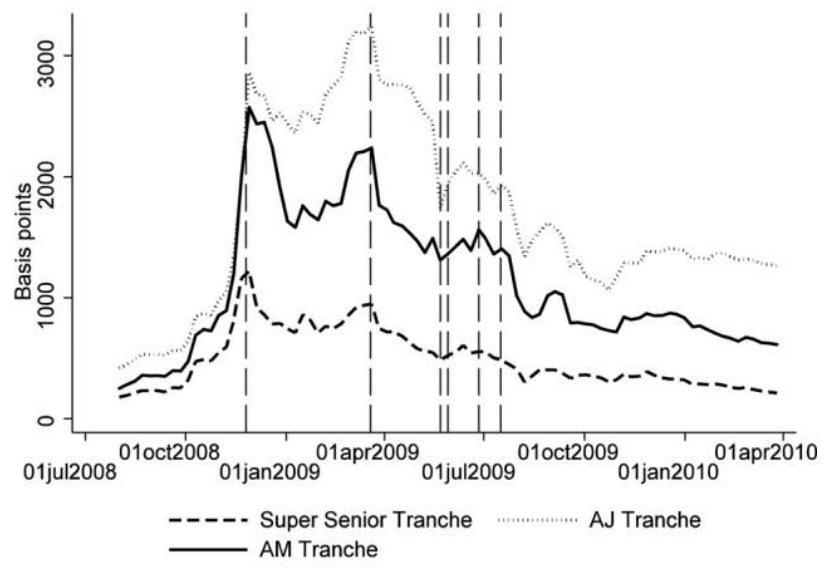

Fig. 6. The yield spread on super senior CMBS bonds, riskier mezzanine AM bonds, and even more junior AJ bonds. The vertical lines represent the key announcement dates, as follows: $11 / 25 / 2008$, initial TALF for ABS, suggesting possible expansion for CMBS; $3 / 19 / 2009$, Legacy securities will be part of TALF; 5/19/2009, super senior legacy fixed rate conduit CMBS eligible for TALF; 5/26/2009, S\&P considers methodology change for fixed rate conduit CMBS; 6/26/2009, S\&P implements new methodology; $7 / 16 / 2009$, first subscription for legacy TALF. 
to super senior fixed-rate conduit CMBS bonds with a AAA credit rating from at least two rating agencies and no lower rating. Despite the fact that the program did not make junior AAA bonds eligible collateral, figure 6 illustrates that spreads for all original AAA bonds continued their rally following the announcement. This broad effect is consistent with the TALF lowering the shadow cost of capital ( $\psi$ in our model) by relieving financial institutions' capital constraints as intended by the Fed.

On May 26, 2009, however, S\&P released a Request for Comment on proposed changes to their rating criteria for fixed-rate conduits. In the release, the rating agency suggested that these changes would put not only junior AAA-rated bonds on negative downgrade watch, but also a significant fraction of super senior bonds just made eligible for the TALF program. While the statement contained no new information about the credit risk of the bonds (it was simply a change in ratings methodology), AAA CMBS spreads retreated broadly following the announcement, since such a rating action would make the bonds ineligible for TALF. Research groups affiliated with CMBS dealers complained in their weekly reports about the action and encouraged the Federal Reserve Bank of New York to drop S\&P as a rating agency for the program.

On June 26, 2009, the rating agency went forward with its proposed changes to criteria and put much of the fixed-rate conduit universe on rating watch negative. Over $90 \%$ of junior AAA bonds were placed on watch, and more than $20 \%$ of super senior bonds were also placed on watch.

One week later, on July 2, the Federal Reserve announced the final program details for the legacy program, which had its first subscription on July 16, 2009. These details clarified that investors would have to have acquired the bond in an arm's-length transaction in the 30 days before the subscription date, a requirement meant to facilitate price discovery. In addition to a standard 3-year TALF loan maturity, the program permitted investors to take out a 5-year loan, which was better suited to the longer dated CMBS collateral. However, the loans came with a carry cap that limited the amount of income that an investor could receive immediately to ensure that the Federal Reserve was paid in full before investors received one dollar of upside.

\section{B. Price Sensitivity to Haircuts: New Survey Evidence}

Figure 6 already provides suggestive evidence on the effect of TALF on market prices, but we need a more rigorous approach to answering the central questions of whether TALF caused yields to narrow and, if so, by how much. We first examine unique survey data on these specific questions, and next examine market prices. 
In March 2009, a survey was conducted among market participants, including both investors and dealers, about how they would value term nonrecourse collateralized loans provided for the purchase of certain CMBS securities. The respondents indicated that lowering haircuts could have a large effect on price and liquidity in the CMBS market. The price effect could be driven by both the value of access to capital, consistent with our model, and the participants' option to walk away from the loan. Since we are interested in the value of access to capital, we focus on the safest securities, which, according to our estimates, had very small risk on a hold-to-maturity basis.

These CMBS bonds are securities backed by a pool of commercial real estate loans. The cash flows from the securities are split into various tranches. We focus on the most senior tranches, those that have priority in case there is not enough money to pay all the tranches. In particular, we focus on the tranches that were rated AAA. Even within the AAA securities, there are differences in seniority, however. The most senior ones-the socalled super senior ones-are called A1, A2, A3, A4, A5, and A1A; the next most senior are called AM (mezzanine within those originally rated AAA, but relatively senior more broadly); and the least senior ones are called $\mathrm{AJ}$ (junior within $\mathrm{AAA}$ ). The $\mathrm{A} 1$ and $\mathrm{A} 2$ receive cash flows earlier than $\mathrm{A} 3, \mathrm{~A} 4$, and $\mathrm{A} 5$, but have the same seniority, while $\mathrm{A} 1 \mathrm{~A}$ receive payments from a different part of the pool as explained in more detail in appendix A.

\section{Losses in Stress Scenarios}

Market participants were asked about their expectations for credit loss in both a "base case" and "stress scenario," each defined by the respondent. Figure 7 shows the distribution of the participants' stress losses for each pool, illustrated using a box plot. The top of each box is the 75th percentile, the bottom of the box is the 25th percentile, the middle line is the median, and the largest and smallest observations are indicated with whiskers.

The figure shows that the median market participants generally thought that pool stress losses would be around $20 \%$, and less than $10 \%$ for the MLMT pool. These overall pool stress loses are small enough that the super senior CMBS bonds would avoid any losses. Indeed, for the super senior bonds to incur losses, each pool must lose more than $30 \%$ of its value, except the 2004 MLMT pool, which was only subordinated at a $20 \%$ rate. (Given that these loans often have recoveries of at least $50 \%$, a $30 \%$ loss requires that more than $60 \%$ of the pool ultimately default.) Focusing on the most pessimistic market participants, only super senior bonds from the 2007 vintage seemed vulnerable to loss. 


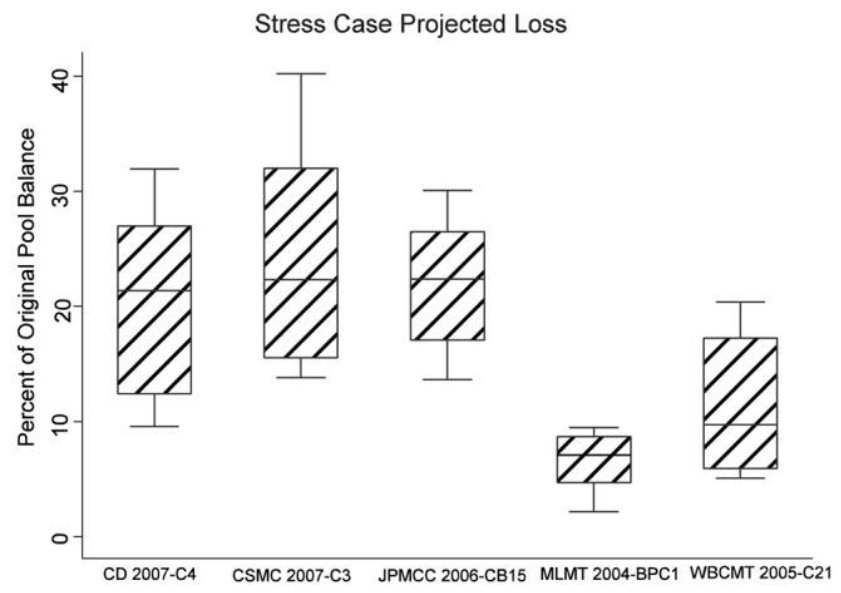

Fig. 7. Distribution of survey responses regarding the potential stress loss of each CMBS pool. In this box plot, the top of each box is the $75 \%$ percentile, the bottom of the box is the $25 \%$ percentile, the middle line is the median, and the largest and smallest observations are indicated with whiskers.

(However, the figure also illustrates that several of the AJ and AM bonds were at risk of loss in a stress scenario.)

\section{Prices and Haircuts}

The key part of the survey asked market participants the amount they would bid for the bond without a Fed facility (their "cash bid"), the amount they would bid under a number of alternative financing arrangements, and their guess at the seller's ask price. In particular, the possible financing arrangements in the survey were Fed-provided collateralized loans with either a low or a high haircut $15 \%$ and $25 \%$ for super senior bonds; $33 \%$ and $50 \%$ for other bonds) using a loan rate of swaps plus 100 basis points, and loan maturity of 3 years, of 5 years, or matching the maturity of the bond.

Table 1 details the mean survey responses for each bond, and our main finding is illustrated more simply in figures $8-11$. In particular, figure 8 shows the price of the super senior (A4) bonds. The $x$-axis has three different haircut options, from low to high: the low haircut proposed in the survey, the high haircut in the survey, and the case of no TALF program (i.e., the market-provided haircut, which is higher than the high survey haircut, often $100 \%$ at that time, meaning that the collateral was not accepted, certainly at those maturities). For simplicity, we normalize the prices by dividing by the no-TALF price (i.e., the cash bid). This is 


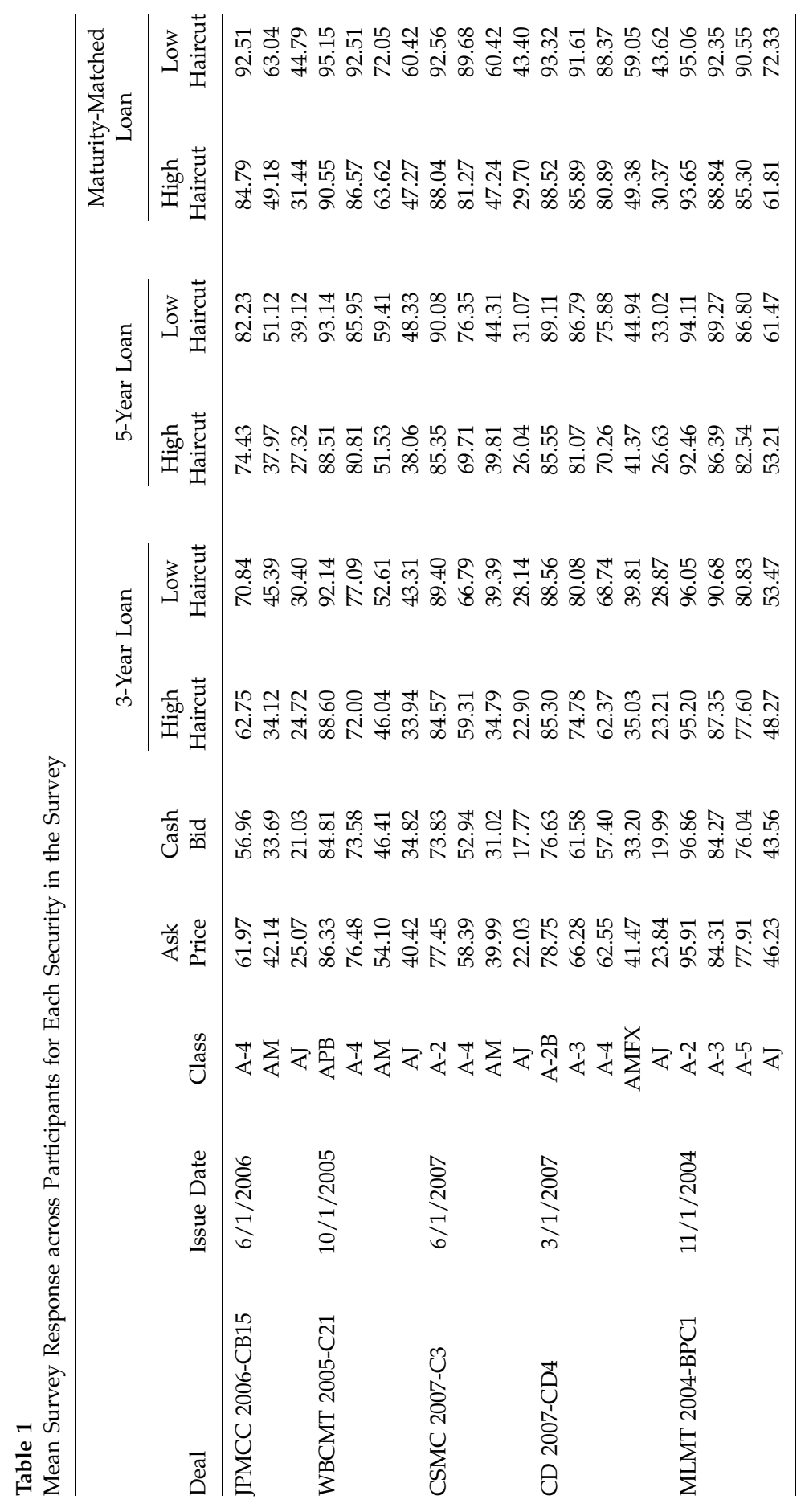




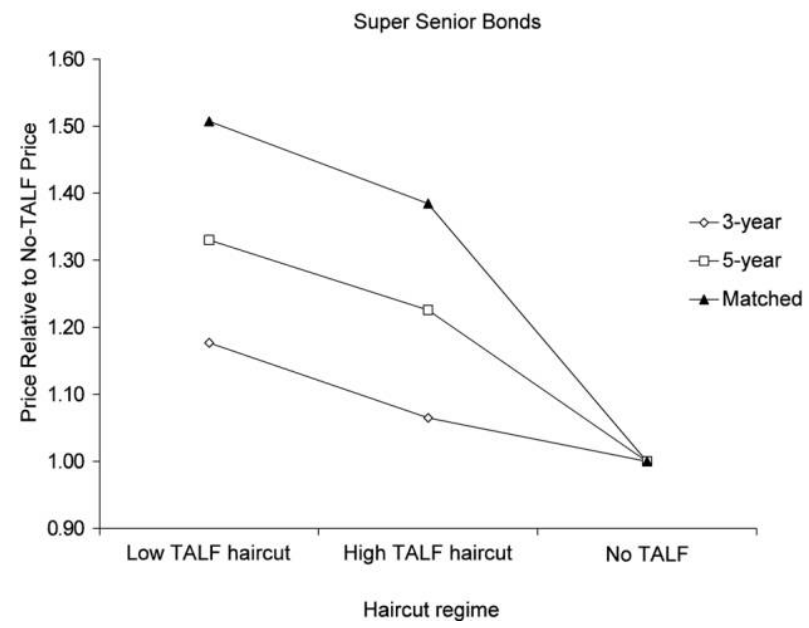

Fig. 8. The figure shows the average survey bid price of super senior CMBS A4 bonds by haircut group. The participants bid the highest price if they have access to a TALF loan with a low-haircut TALF, lower if the TALF loan has a high haircut, and lowest if they do not have access to TALF. All prices are normalized by the no-TALF price. The three lines correspond to a 3-year TALF loan, a 5-year TALF loan, or a maturity-matched TALF loan (longest).

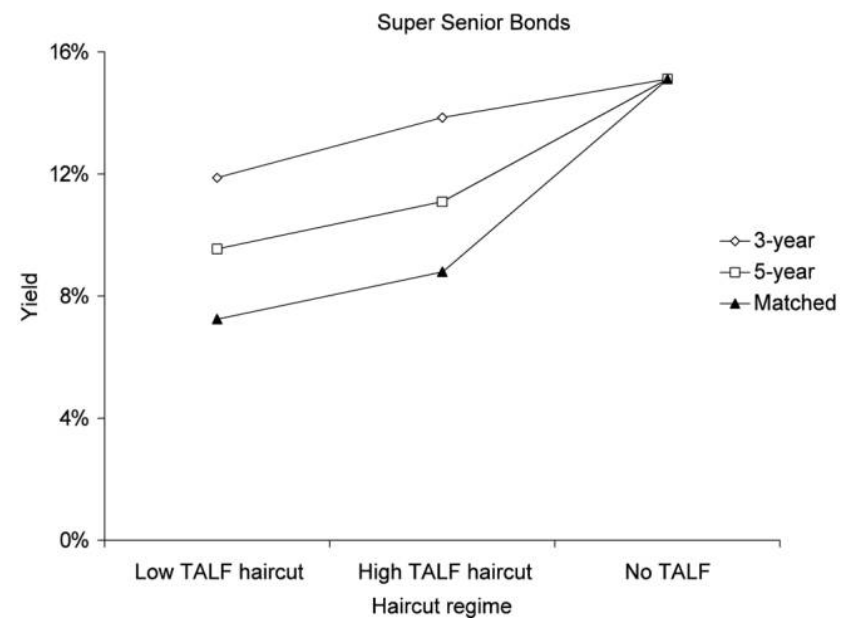

Fig. 9. The figure shows the annual yields corresponding to the average survey bid price of super senior CMBS A4 bonds by haircut group. The yield (i.e., the required return) is lowest with a TALF loan with a low-haircut TALF, higher if the TALF loan has a high haircut, and highest if there is no TALF. The three lines correspond to a 3-year TALF loan, a 5-year TALF loan, or a maturity-matched TALF loan (longest). 


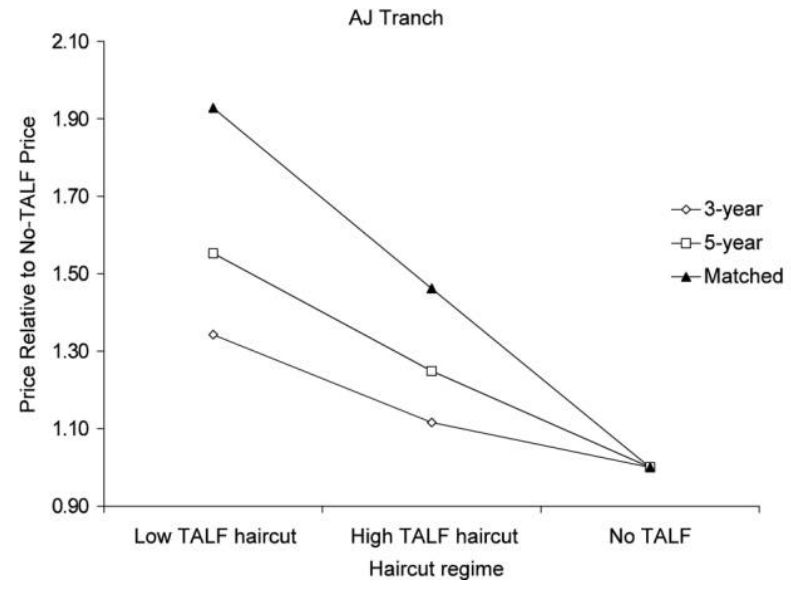

Fig. 10. The figure shows the average survey bid price of CMBS AJ bonds by haircut group. The participants bid the highest price if they have access to a TALF loan with a low-haircut TALF, lower if the TALF loan has a high haircut, and lowest if they do not have access to TALF. All prices are normalized by the no-TALF price. The three lines correspond to a 3-year TALF loan, a 5-year TALF loan, or a maturity-matched TALF loan (longest).

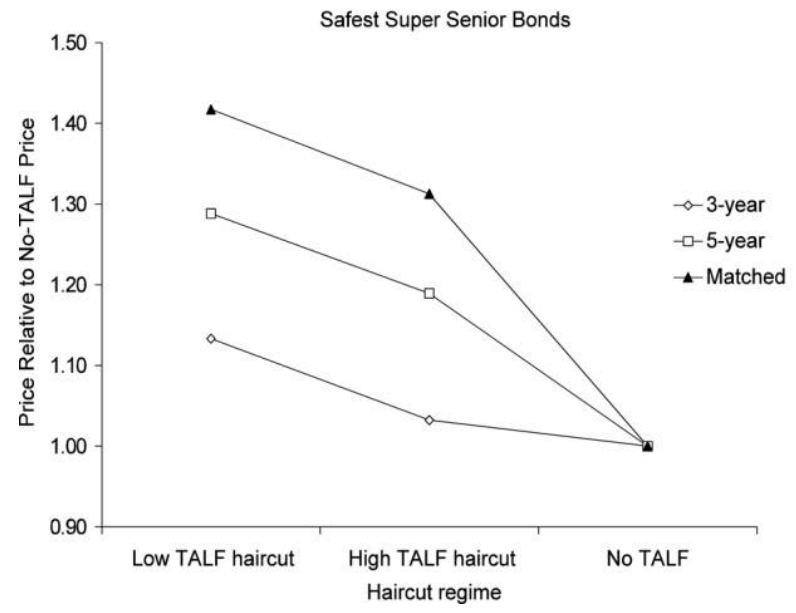

Fig. 11. The figure shows the average survey bid price of the safest super senior CMBS A4 bonds by haircut group. The participants bid the highest price if they have access to a TALF loan with a low-haircut TALF, lower if the TALF loan has a high haircut, and lowest if they do not have access to TALF. All prices are normalized by the no-TALF price. The three lines correspond to a 3-year TALF loan, a 5-year TALF loan, or a maturitymatched TALF loan (longest). 
illustrated for 3-year loans, 5-year loans, and maturity-matched loans (approximately 10-year loans).

We see that lower haircuts are associated with substantially higher prices, and, the longer the loan, the larger the effect. With a 3-year loan with a high haircut, respondents say they are willing to pay $6 \%$ more for these securities. If the haircut is lowered, their bid increases to $18 \%$ over their cash bid, a strikingly large effect. If the loan is extended to 5 years, the price premium increases to $33 \%$, and a maturity-matched loan has a $51 \%$ premium. This strong price sensitivity to the maturity of the loan is consistent with a fear of having to refinance the collateral in a bad market, which was expressed by the investors in follow-up discussions.

These prices can also be expressed in terms of annualized yield to maturity as we do in figure 9 . The average yield of these bonds was around $15 \%$ at the time of the survey (about $12 \%$ above the swap rate at that maturity). Having access to a 5-year term loan lowers the yield to $11 \%$ with a high haircut, and to $9.5 \%$ at a low haircut. To put these numbers in perspective, recall that during the crisis, the Fed lowered the Fed funds rate from $5.25 \%$ in early 2007 all the way to the zero lower bound $(0 \%-0.25 \%)$. If the TALF could lower the yields by several percentage points as our survey suggests, then it is a powerful tool.

Figure 10 shows that the effect of access to leverage is much stronger on the lower priced AJ bonds. In some extreme cases, the bid price more than doubles with the TALF program, relative to the bid price without it. This stronger effect could be due to the fact that these bonds were even more difficult to finance in the market, or because of the value of walking away from the loan.

To really focus on the shadow value of capital, figure 11 plots the results for only the safest super senior bonds, namely those that were significantly overcollateralized, even beyond the most pessimistic respondent's stress scenario. Taking the responses at face value, this means that any losses on these bonds would be unlikely, and in the unlikely event of a loss, recovery rates would likely be high.

We see that the price effect of lowering haircuts is large even in the case of the safest super senior bonds, consistent with the program relieving a binding margin requirement for financial institutions. This interpretation is consistent with follow-up discussions with market participants in which they described their methodologies. The typical firm used discount rates over $20 \%$ even for risk-free cash flows that had to be completely funded with the firm's own capital. Finally, table 1 also shows that survey-based ask prices were significantly above cash bid prices, illustrating market illiquidity. 


\section{Do Haircuts Affect Market Prices?}

Having established a strong link between haircuts and prices in survey data, we next consider how market prices reacted to the program. As discussed above, yields narrowed significantly around the introduction of the program, but many other events occurred at the same time. Hence, to assess the causality of haircuts on market prices, we apply a finer statistical tool. Specifically, we consider the market response to news that a bond is rejected from use in the TALF program.

This strategy is based on the fact that TALF was available only for AAArated super senior bonds accepted by the Fed after a review of the credit risk of the loan. When a bond was rejected, it would not benefit from the program's low haircuts, and, therefore, our model predicts that its yield should rise by an amount that is increasing in the shadow cost of capital.

We note that the Fed's decision is unlikely to have conveyed private information about the bonds. While the Fed employed outside vendors with expertise in commercial real estate, the risk assessment process used only information available from publicly available prices, offering documents, and servicing reports.

The decision to reject bonds was nevertheless news to the market, as market participants were generally confounded by which bonds were rejected. For example, investment bank research that discussed the efficacy of the risk assessment procedures denoted the process as a "black box" and, following the November 2009 subscription, Citi wrote, "So once again we come up short in trying to understand the Fed's rejection process" (Berenbaum, Gaon, and Mather 2009, 3).

To assess the impact of TALF eligibility, we run the following regression using weekly data on yield spreads of approximately 1,600 super senior fixed-rate conduit bonds from August 2008 through March 2010, with standard errors corrected for heteroskedasticity and clustered at the security level:

$$
\begin{aligned}
\Delta \text { spread }_{j, t}= & \sum_{k=0}^{4} c_{k}^{r} 1(\text { reject })_{j, t-k}+\sum_{k=0}^{4} c_{k}^{a} 1(\text { accept })_{j, t-k} \\
& +\sum_{k=1}^{4} c_{k}^{\Delta} \Delta \operatorname{spread}_{j, t-k}+f e_{j, t}+\varepsilon_{j, t} .
\end{aligned}
$$

The dependent variable is each bond $j$ 's change in yield spread during week $t$, the $c^{\prime}$ s are regression coefficients, and the explanatory variables are indicator functions for whether this bond was rejected during the current week or any of the previous four weeks, indicator functions for 
whether the bond was accepted during the same time periods, lagged yield changes, and fixed effects $\left(f e_{j, t}\right)$ for each combination of week, vintage, and security class. The interpretation of the coefficients on the rejection dummies is the effect of rejection on the change in yield spread, over and above the general market yield changes for nonsubmitted bonds of that security class and vintage during that week (captured by the fixed effects), and similarly for the acceptance dummies.

Figure 12 shows the estimated response of spreads to being rejected or accepted from the TALF program. We construct this graph by setting the initial yield spread to $300 \mathrm{bps}$ and then tracing the response to a TALF decision by iterating equation (29) using the estimated coefficients. The initial response to a rejection is a statistically significant rise in the yield spread by over $20 \mathrm{bps}$, and this effect is reduced to 3 bps over time. The larger initial effect could be due to price pressure associated with selling by agents who will only hold the bonds if they can get access to leverage. In contrast, the effect of TALF acceptance is only about $5 \mathrm{bps}$ and appears mostly temporary. The larger effect of rejection can be explained by the fact that only a small fraction of bonds was rejected (between $1 \%$ and $10 \%$, except in the last weeks of the program), so a rejection is more surprising.

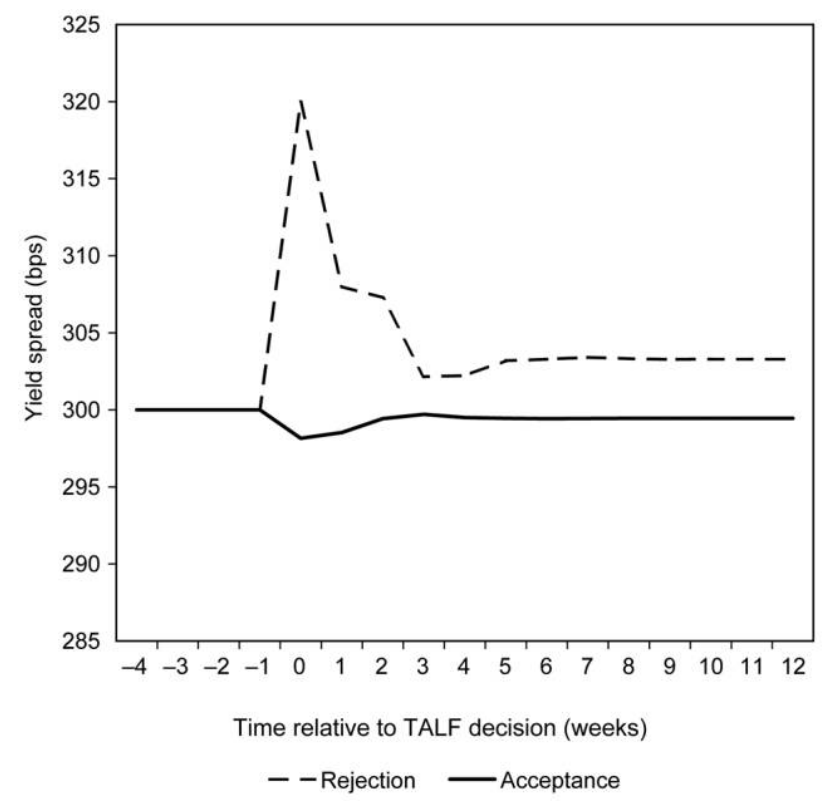

Fig. 12. The price effect of TALF rejections. This figure shows the yield-spread response of CMBS bonds that are accepted or rejected from the TALF program. The yield spread of rejected bonds rises after the decision, as these bonds will not benefit from the low haircuts provided by TALF. 
The model implies that financing terms (i.e., access to low haircuts) are more important when the shadow cost of capital is high, that is, during times of binding capital constraints. To investigate this implication, figure 13 considers the effect of TALF rejections separately for the early subsample (July 2009 through September 2009) and the late subsample (October 2009 through March 2010) by estimating equation (29) separately for each period. The early period includes what appeared to be the end of the 2007-9 U.S. banking crisis, while banks and the economy were doing better in many respects during the later period (e.g., lower TED spreads, rising stock market).

Figure 13 shows that the effect of TALF rejections was much larger in the early period. During the early period, a rejection was followed by a statistically significant 80 bps increase in yield spreads, and the effect eventually went down to about $40 \mathrm{bps}$. During the later sample, the impact of a rejection was smaller and more transitory, with an immediate impact of only $15 \mathrm{bps}$. Hence, it appears that the legacy TALF program

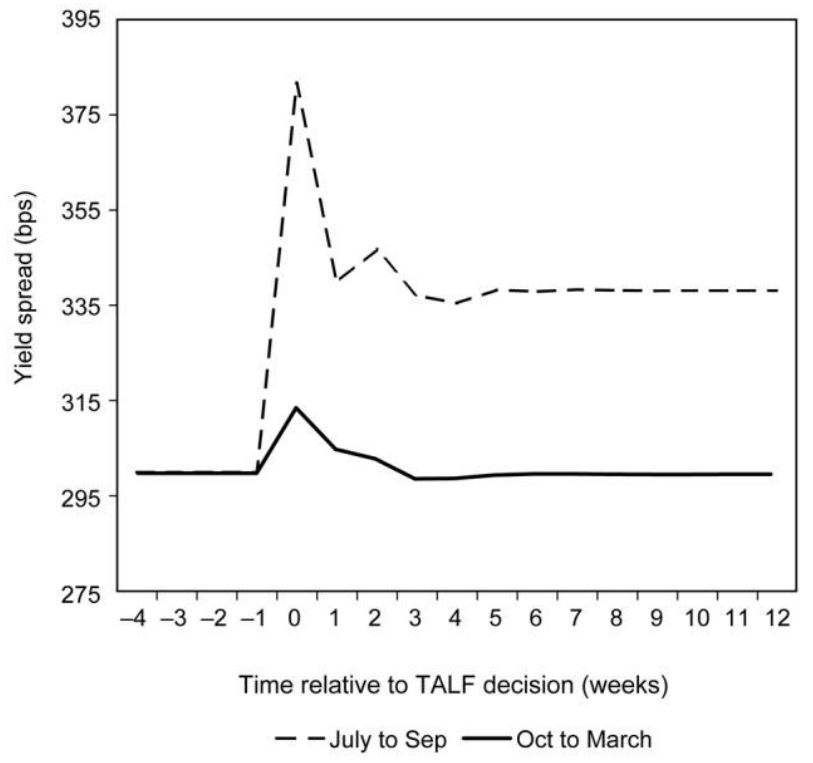

Fig. 13. The price effect of TALF rejections by subsample. This figure shows the yield-spread response of CMBS bonds that are rejected from the TALF program for, respectively, the period from July to September 2009 (the ending of the financial crisis) and from October 2009 to March 2010 (when the banking crisis was mostly over). The effect of rejections is significantly larger in the former period, consistent with the model's prediction that haircuts have a larger effect on prices when capital constraints are tight and the shadow cost of capital is high. 
had a significant impact on CMBS spreads, at least for the first 3 months of the program, when capital constraints were still tight. As liquidity returned to the markets, the liquidity provided by the program became less important. The dependence of the rejection effect on liquidity provides another argument against the rejection effect being driven by information.

\section{Conclusion: Two Monetary Tools}

We model how required returns increase when credit suppliers hit their margin constraints, reducing economic activity and propagating business cycles. The effect is largest for illiquid assets that are difficult to finance in a crisis, that is, assets with high haircuts.

Surprisingly, while an interest rate cut reduces the required return for liquid low-margin assets, it can increase the required return for illiquid high-margin assets. This is because the lower interest rate increases the desire for leverage and, as a result, increases the shadow cost of capital. This effect increases the required return for high-margin assets, countervailing the direct effect of the interest rate cut.

A haircut cut, however, always reduces the required return on the affected asset and stimulates real activity in that sector. This can be achieved if the central bank accepts such securities as collateral in exchange for loans. Hence, haircuts provide a second monetary policy tool in addition to the standard interest rate tool.

While haircuts can be decreased in crises by offering loans at moderate haircuts, they cannot be similarly increased in good times when credit might be excessive. Indeed, if a central bank offers collateralized loans at high haircuts, borrowers can simply get their loans elsewhere. However, in addition to the market-imposed margin constraints, financial institutions also face regulatory capital requirements that can be captured in our framework in a straightforward way. ${ }^{10}$ Hence, to reduce business cycles, a central bank may need capital requirements in good times and lending facilities that stand ready in periods of liquidity crisis.

We examine empirically the effectiveness of the second monetary tool, studying the natural experiment of the introduction of the TALF lending facility. We find strong effects of providing collateralized loans at low haircuts. Survey evidence shows that yields on affected securities might drop as much as $5 \%$ at the height of the crisis, illustrating a significant demand sensitivity to haircuts. 
We also consider the effect on actual market prices of TALF. To isolate the effect of TALF, we estimate the change in yield following the Fed's unpredictable announcement of a bond's acceptance or rejection from the program. The yield spread of rejected bonds rises significantly relative to other bonds, and the rejection effect is largest during crisis times when the shadow cost of capital is high.

This approach estimates the effect of moving certain securities down the haircut-return curve (fig. 5) by reducing their haircuts. Another important potential benefit of lending programs is that they can reduce the required compensation for tying up capital more broadly, that is, flattening the haircut-return curve (fig. 5 and proposition 4 ) because the program improves the funding conditions of constrained agents. Consistent with this consideration, the yields on both affected and unaffected securities went down when it was announced that legacy TALF was being considered, down when legacy TALF was confirmed, up when a rating-methodology change made TALF less applicable, and finally down when TALF was actually implemented.

The total effect of the haircut tool is thus to move securities down the haircut-return curve and to flatten the curve itself, reducing the yield on securities, which in turn improves the credit supply to the real economy. In the data, as in the model, this monetary tool appears to be effective during crises.

\section{Appendix A}

\section{A Background on CMBS Securities}

CMBS bonds are securities backed by a pool of commercial real estate loans. The cash flows from the securities are split into various tranches. We focus on the most senior tranches, those that have priority in case there is not enough money to pay all the tranches. In particular, we focus on the tranches that were originally rated AAA (and, as we will see, continued to be rated AAA for the most part). Even within the AAA securities, there are differences in seniority, however. The most senior ones-the so-called super senior ones-are called A1, A2, A3, A4, A5, and A1A; the next most senior are called AM (mezzanine within AAA, but relatively senior more broadly); and the least senior ones are called AJ (junior within AAA). The $\mathrm{A} 1$ and $\mathrm{A} 2$ receive cash flows earlier than $\mathrm{A} 3$ and $\mathrm{A} 4$, but have the same seniority, while $\mathrm{A} 1 \mathrm{~A}$ receive payments from a different part of the pool, as explained below. 
The real estate loans in the pool underlying fixed-rate conduit CMBS have a fixed interest rate; a maturity of 5, 7, or 10 years; and amortization schedule over 30 years (implying a principal payment at maturity). The loan pool typically includes more than 100 loans, but the largest 10 loans can represent $40 \%$ of the overall balance. While the pool can be diversified by geography and property type, given the balloon nature of the loans there is correlated refinancing risk. The so-called super senior tranches generally had $30 \%$ subordination at issue in the most recent vintages (i.e., starting in 2005) but had as little as $20 \%$ subordination in earlier vintages. In contrast, the AM and AJ tranches, each which also had AAA ratings at issue, only had $20 \%$ and $12 \%$ subordination, respectively. These bonds have structural leverage given their subordination to the super senior class, which makes it possible for investors to incur losses of $100 \%$.

The loan pool underlying fixed-rate conduit CMBS is often tranched into one pool of multifamily loans and another pool of all other loans. Principal payments from the multifamily loans are directed to the A1A tranche. Given the involvement of the government-sponsored enterprises in agency-sponsored multifamily CMBS issues, it should not be surprising that loans in this pool are generally adversely selected from the multifamily universe. Cash flows from other property types (office, retail, industrial, etc.) are directed to sequential-pay super senior classes, which generally included A1, A2, A3, and A4. Upon receipt, principal is first distributed to the $\mathrm{A} 1$ tranche until it paid in full, and then to the A2 tranche. This time tranching makes the $\mathrm{A} 1$ and $\mathrm{A} 2$ bonds have shorter average lives (5 years) and the $\mathrm{A} 3$ and $\mathrm{A} 4$ bonds longer average lives (10 years). Despite the time tranching, all of these bonds are structurally senior. In particular, if credit losses on the overall loan pool rise above $30 \%$, the allocation of losses and principal from that point in time goes pro rata among the super senior tranches. The survey instrument focused on AAA-rated tranches from five fixed-rate conduit CMBS deals illustrated in table A1. 


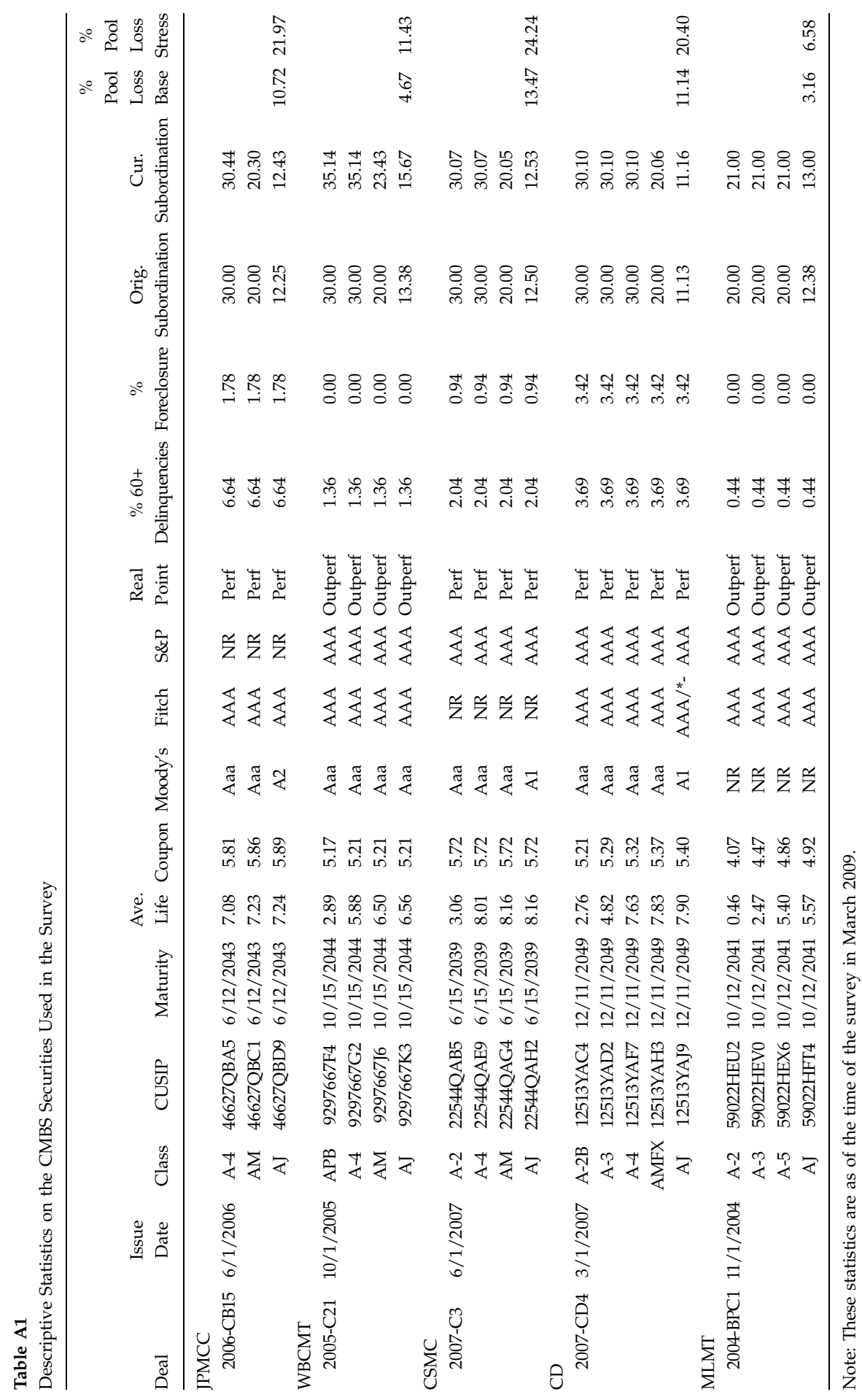




\section{Appendix B}

\section{Proofs}

Proof of Proposition 1. Given the constraint (eq. [6]), the first-order condition for the portfolio choice is

$$
0=E_{t}\left(\bar{P}_{t+1}\right)-P_{t}\left(1+r^{f}\right)-\gamma^{n} \Sigma_{t} \theta-\psi_{t}^{n} D\left(y_{t}^{n}\right) D\left(m_{t}\right) P_{t},
$$

where $y_{t}^{n, i}=1$ if $\theta^{i}>0, y_{t}^{n, i}=-1$ if $\theta^{i}<0$, and $y_{t}^{n, i} \in[-1,1]$ if $\theta_{t}^{i}=0$. Under the assumption that $W^{a}$ is sufficiently large, agent $a$ is unconstrained; that is, $\psi_{t}^{a}=0$, and equating aggregate supply and demand gives a more general version of equation (14) in the text: ${ }^{11}$

$$
\begin{gathered}
E_{t}\left[r_{t+1}\right]-\left[r^{f}+\psi_{t} x D\left(y_{t}\right) D\left(m_{t}\right)\right]=\gamma D\left(P_{t}\right)^{-1} \Sigma \bar{\theta} \\
=\gamma P_{t}^{\mathrm{mkt}} \operatorname{Cov}_{t}\left(r_{t+1}, r_{t+1}^{\mathrm{mkt}}\right) .
\end{gathered}
$$

Aggregating (B3), that is, premultiplying by $q^{\top}$, gives

$$
E_{t}\left[r_{t+1}^{\mathrm{mkt}}-\left(r^{f}+\psi_{t} x m_{t}^{\mathrm{mkt}}\right)\right]=\gamma P_{t}^{\mathrm{mkt}} \operatorname{Var}_{t}\left(r_{t+1}^{\mathrm{mkt}}\right),
$$

where $m_{t}^{\mathrm{mkt}}$ is the market value weighted haircut $m$, taking into account the sign $y$ of the constrained agent's position:

$$
m_{t}^{\mathrm{mkt}}=q_{t}^{\top} D\left(y_{t}\right) m_{t} .
$$

Combining (B3) and (B4) yields the result in the proposition, given that $y_{t}^{i}=1 \forall i, t$.

Proof of Proposition 2. Let $\bar{W}^{b}$ denote the wealth invested by agent $b$ in the risky assets when not constrained. If the realization of the productivity vector $A_{t}$ is low enough, then $W_{t}^{b}<\bar{W}^{b}$; that is, agent $b$ becomes constrained, and the investment level changes. (According to proposition 5 , investment actually decreases, in all sectors, under the additional assumptions that $\Sigma_{A}$ is diagonal and $\alpha+\beta=1$.) Consequently, the reduced output due to the low productivity shock predicts a level of output different from the average output.

The proofs of propositions $3-5$ are based on the following three equilibrium restrictions: the optimality of aggregate demand (eq. [12]), the 
first-order condition for agent $a$ 's demand (eq. [10]), and the binding margin constraint of agent $b$ (eq. [6]):

$$
\begin{gathered}
0=-\left(I_{t}^{i}\right)^{1-\alpha}\left(1+r_{t}^{f}+\psi_{t} x m_{t}^{i} y_{t}^{i}\right)+\bar{A}^{i}-\gamma \Sigma_{A}^{i}\left(I_{t}^{i}\right)^{\alpha} \bar{\theta}^{i}, \\
0=-\left(I_{t}^{i}\right)^{1-\alpha}\left(1+r_{t}^{f}\right)+\bar{A}^{i}-\gamma^{a} \Sigma_{A}^{i}\left(I_{t}^{i}\right)^{\alpha} \theta_{t}^{i, a}, \\
0=\sum_{i} m_{t}^{i}\left(\bar{\theta}^{i}-\theta_{t}^{i, a}\right) \frac{1-\beta}{\alpha} I_{t}^{i}-W_{t}^{b} .
\end{gathered}
$$

Equation (B5) is accompanied by the complementary slackness condition $\left(1+y_{t}^{i}\right)\left(1-y_{t}^{i}\right) \theta_{t}^{i, b}=0$, in addition to the restriction $y_{t}^{i} \in[-1,1]$. Comparing (B5) and (B6) shows that, since $\gamma^{a}>\gamma, y_{t}^{i}>0$ : otherwise $\theta_{t}^{i, a}<\bar{\theta}_{t}^{i}$, that is, $\theta_{t}^{i, b}>0$, which means $y_{t}^{i}>0$-this would be a contradiction. Note the implication that there is no shorting in equilibrium.

If $\theta^{i, b}>0$ for all $i$, then we have a system of $J+J+1$ equations, to be solved for the same number of unknowns, namely, agent $a^{\prime}$ s security positions $\left(\theta^{1, a}, \ldots, \theta^{J, a}\right)$, the firms' investments $\left(I^{1}, \ldots, I^{J}\right)$, and the shadow cost of capital $\psi$. We have eliminated agent $b^{\prime}$ 's security positions using the equilibrium relation $\theta^{i, a}+\theta^{i, b}=\bar{\theta}^{i}$, and we have eliminated share prices using $P_{t}^{j}=[(1-\beta) / \alpha] I_{t}^{j}$ from equation (24). The same conclusion holds in general, noting that for every $i$ such that $\theta^{b, i}=0$, an unknown $y^{i}$ is introduced.

Proof of Proposition 3. Suppose first $\gamma^{a}=\infty$; that is, agent $b$ is the sole investor in risky assets. A decrease in $r_{t}^{f}$ must be accompanied by increases in $I_{t}^{i}$ for some $i$ and decreases for other $i$, in order to preserve the satisfaction of the margin constraint (B7). $I_{t}^{i}$ decreases, however, if and only if $r_{t}^{f}+\psi_{t} m_{t}^{i}$ increases. It follows that $\psi_{t}$ increases, and that $r_{t}^{f}+$ $\psi_{t} m_{t}^{i}$ increases if and only if $m_{t}^{i}$ is large enough. Reasoning by continuity, we infer that the results hold also when the risk tolerance $\left(\gamma^{a}\right)^{-1}$ is close enough to zero.

A more general result can be derived. In particular, for any value $\gamma^{a}$, it holds that, if $\theta_{t}^{i, b}>0$, then $\partial\left(r_{t}^{f}+\psi_{t} m_{t}^{i}\right) / \partial r_{t}^{f}>0$, and therefore $\partial I_{t}^{i} / \partial r_{t}^{f}<0$, for $m_{t}^{i}$ below a certain threshold, possibly equal to 1 . If $\theta_{t}^{i, b}=0$, then $\partial I_{t}^{i} / \partial r_{t}^{f}<0$.

Proof of Proposition 4. (a) Suppose first that $\theta_{t}^{j, b}>0$. A decrease in $m_{t}^{j}$ implies that $\left(1-\theta_{t}^{i, a}\right) I^{i}$ increases for some $i$, so that $I^{i}$ increases. If $i \neq j$, equation (B5) then implies that $\psi_{t}$ decreases, so that $I_{t}^{i}$ increases for all $i$ such that $\theta_{t}^{i, b}>0$. In the case $\theta_{t}^{i, b}=0, I^{i}$ may only increase, since $\theta_{t}^{i, b}$ and $I^{i}$ react in the same direction, and $\theta_{t}^{i, b} \geq 0$. 
If $I_{t}^{i}$ decreases for all $i \neq j, \theta_{t}^{i, b}>0$, which implies that $\psi_{t}$ increases, then it must be the case that either $I_{t}^{j}$ increases (and therefore $\psi_{t} m_{t}^{j}$ decreases), or $I_{t}^{i}$ with $\theta_{t}^{i, b}=0$ increases. The latter is impossible, though, since it requires that $\psi_{t} m_{t}^{i} y_{t}^{i}$ decreases, while $\psi_{t}$ increases, as does $y_{t}^{i}$ (from some value in $[-1,1]$ to 1 , since $\theta_{t}^{i, a}$ decreases with a fall in $I_{t}^{i}$, and therefore $\theta_{t}^{i, b}$ becomes strictly positive).

Suppose now that $\theta_{t}^{j, b}=0$. Then either the decrease in $m_{t}^{j}$ has no impact, or $\theta_{t}^{j, b}$ becomes strictly positive, while $I^{j}$ increases. The effect on $I_{t}^{i}$ for $i \neq j$ is as above.

(b) Suppose first that $\theta^{j, b}>0$. If $m_{t}^{j}$ becomes 0 , then $\left(1-\theta_{t}^{j, a}\right) I^{i}$ increases for some $i \neq j$, which, following the first steps above, leads to a decreased $\psi_{t}$ and higher investment in all assets. If, on the other hand, $\theta_{t}^{j, b}=0$, then $I_{t}^{j}$ clearly increases, while all other investments are unaffected.

Finally, if all haircuts $m_{t}^{i}$ are lowered by the same fraction $\varepsilon \in(0,1)$, then some product $\left(1-\theta_{t}^{i_{0}, a}\right) I^{i_{0}}$ increases, so that $\psi_{t} m_{t}^{i_{0}}$ decreases, which implies that $\psi_{t} m_{t}^{i}$ decreases for all $i$.

Proof of Proposition 5. (a) Equation (B7) implies that an increase in $W^{b}$ must be accompanied by a decrease in $\theta^{i, a}$ or an increase in $I^{i}$ for some $i$. Equation (B6) implies that $\theta^{i, a}$ and $I^{i}$ are negatively related to each other, so that, for some $i$, both $\theta^{i, a}$ decreases and $I^{i}$ increases.

Finally, from (B5) it follows that the increase in $I^{i}$ must be offset by a decrease in $\psi$. For all $j \neq i$ with $\theta^{j, b}>0$, therefore, $I^{j}$ must also increase. If $\theta^{j, b}=0$, then $I^{j}$ does not change as long as $\theta^{j, b}$ does not.

(b) If $\bar{\theta}^{i}$ goes down, then either $\theta^{i, a}$ or $\theta^{i, b}$ must decrease. If $\theta^{i, a}$ decreases, then $I^{i}$ must increase (by [B6]). If $\theta^{i, b}$ decreases, then either $I^{i}$ increases or $\theta^{j, b} I^{j}$ increases for some $j \neq i$. In this case, then, $I^{j}$ increases, and therefore $\psi$ decreases, which implies that $\theta^{i, b}$ increases, which is a contradiction. We conclude that $I^{i}$ increases. Note that investments in the other technologies either all increase or all decrease. If $\bar{\theta}^{i}$ becomes 0 , then $\theta^{j, b} I^{j}$ increases for some $j \neq i$, so that $\psi$ must decrease, implying that $I^{j}$ increases for all $j$ with $\theta^{j, b}>0$.

\section{Appendix C}

\section{Data Sources}

The survey was conducted by one of the authors in mid-March 2009 of eight market participants, including CMBS dealers as well as money managers who traded CMBS.

The econometric analysis exploits a proprietary data set on endof-week prices for more than 2,000 originally rated AAA tranches of 
the outstanding fixed rate conduit universe for 2009, as well as credit ratings actions on those tranches for the same time period.

\section{Endnotes}

We are grateful for useful discussions with Tobias Adrian, Darrell Duffie, Livia Levine, Guido Lorenzoni, Andrei Shleifer, and Michael Woodford as well as from participants at the Liquidity Working Group at the Federal Reserve Bank of New York, the Conference on Financial Frictions and Macroeconomic Modeling, Cowles Foundation Conference in General Equilibrium and Its Applications, the annual meeting of the American Economic Association, the Money and Banking Workshop at the University of Chicago Department of Economics, New York University, the Stockholm School of Economics, and University of California at Berkeley.

1. To understand the meaning of a haircut, suppose that before the crisis, a financial institution could borrow $\$ 98$ with a $\$ 100$ bond as collateral. The $\$ 2$ difference is the lender's extra margin of safety and is called a $2 \%$ haircut. This allows the borrower up to 50 -to- 1 leverage. If the haircut went to $20 \%$, the institution would need to finance $\$ 20$ of the position with its own capital and could only support a 5-to-1 leverage.

2. See also the related literatures in corporate finance and banking: Shleifer and Vishny (1992), Allen and Gale (1998, 2004, 2005), and Holmström and Tirole (1998, 2001).

3. The Talmud provides further detail on how the haircut should be treated in the event of default: "Rav Huna: If this condition was made when the money was given, then it is binding, even if the field is worth more than the loan. If the condition was made after the money was given, then the lender can only take the portion of the land equivalent to the value of the loan" (Babylonian Talmud Bava Metzia 66a-66b).

4. If depreciation is only partial, and disinvestment is costless following production, then the results are qualitatively the same.

5. Given that markets are incomplete, different types of agents may employ different pricing kernels, but the homogeneity of the production function means that, since they agree on the current price of the firm, they also agree on the optimal investment policy.

6 . The results do not rely on this utility function. Indeed, preferences are mainly used below to derive the required return as a margin CAPM, and an almost identical margin CAPM relationship is derived with constant relative risk aversion in continuous time in Gârleanu and Pedersen (forthcoming). Further, Cuoco (1997) derives a modified CAPM for general convex constraints and general preferences.

7. Equation (9) holds if the optimal choice $\theta^{n}$ is strictly positive, which appears the most natural case. We state proposition 1 under this assumption. In appendix B, we provide the complete result.

8. For any vector $v \in \mathbb{R}^{J}, D(v)$ is a diagonal $J \times J$ matrix with $(j, j)$ entry $v_{j}$.

9. More general results hold, but we omit them in the interest of simplicity.

10. Regulatory requirements are mathematically of a similar form: $\sum_{i} m_{t}^{\text {Reg, } i}\left|\theta_{t}^{i}\right| P_{t}^{i} \leq$ $W_{t}$, where $m_{t}^{\text {Reg, } i}$ is the regulatory capital requirement for security $i$.

11. We use the notation $\psi^{b}=\psi$ and $y^{b}=y$.

\section{References}

Acharya, V. V., and L. H. Pedersen. 2005. "Asset Pricing with Liquidity Risk." Journal of Financial Economics 77:375-410.

Adrian, T., E. Moench, and H. Shin. 2010. “Financial Intermediation, Asset Prices and Macroeconomic Dynamics." Staff Report no. 422, Federal Reserve Bank of New York.

Adrian, T., and H. S. Shin. 2008. "Liquidity and Leverage." Staff Report no. 328, Federal Reserve Bank of New York. 
2010. "Financial Intermediaries and Monetary Economics." Staff Report no. 398, Federal Reserve Bank of New York.

$\rightarrow$ Aiyagari, S., and M. Gertler. 1999. "Overreaction of Asset Prices in General Equilibrium." Review of Economic Dynamics 2, no. 1:3-35.

$\rightarrow$ Allen, F., and D. Gale. 1998. "Optimal Financial Crisis." Journal of Finance 53, no. $4: 1245-84$.

$\rightarrow-$. 2004. "Financial Intermediaries and Markets." Econometrica, 72, no. 4:1023-61.

$\rightarrow$. 2005. "Financial Fragility, Liquidity, and Asset Prices." Journal of the European Economic Association 2, no. 6:1015-48.

$\rightarrow$ Amihud, Y., and H. Mendelson. 1986. "Asset Pricing and the Bid-Ask Spread." Journal of Financial Economics 17, no. 2: 223-49.

$\rightarrow$ Ashcraft, A. 2005. "Are Banks Really Special? New Evidence from the FDICInduced Failure of Healthy Banks." American Economic Review 95, no. 5:1712-30.

Bagehot, W. 1873. Lombard Street: A Description of the Money Market. London: King.

Berenbaum, J., S. Gaon, and J. Mather. 2009. “November TALF Sees Three Rejections as Acceptance Criteria Remain Elusive." Citi CMBS Weekly, November 25.

$\rightarrow$ Bernanke, B., and M. Gertler. 1989. "Agency Costs, Net Worth, and Business Fluctuations." American Economic Review 79, no. 1:14-31.

Bernanke, B., M. Gertler, and S. Gilchrist. 1998. "The Financial Accelerator in a Quantitative Business Cycle Framework." Working Paper no. 6455, NBER, Cambridge, MA.

$\rightarrow$ Brunnermeier, M., and L. H. Pedersen. 2009. "Market Liquidity and Funding Liquidity." Review of Financial Studies 22:2201-38.

$\rightarrow$ Caballero, R., and A. Krishnamurthy. 2001. "International and Domestic Collateral Constraints in a Model of Emerging Market Crises." Journal of Monetary Economics 48, no. 3:513-48.

$\rightarrow$ Coen-Pirani, D. 2005. "Margin Requirements and Equilibrium Asset Prices." Journal of Monetary Economics 52, no. 2:449-75.

$\rightarrow$ Cuoco, D. 1997. "Optimal Consumption and Equilibrium Prices with Portfolio Constraints and Stochastic Income." Journal of Economic Theory 72, no. 1:33-73.

Cúrdia, V., and M. Woodford. 2009. "Credit Frictions and Optimal Monetary Policy." Working paper, Columbia University.

$\rightarrow$ Detemple, J., and S. Murthy. 1997. "Equilibrium Asset Prices and No-Arbitrage with Portfolio Constraints." Review of Financial Studies 10, no. 4:1133-74.

$\rightarrow$ Duffie, D., N. Gârleanu, and L. H. Pedersen. 2005. "Over-the-Counter Markets." Econometrica 73:1815-47.

$\rightarrow$. 2007. "Valuation in Over-the-Counter Markets." Review of Financial Studies 20:1865-1900.

$\rightarrow$ Fostel, A., and J. Geanakoplos. 2008. "Leverage Cycles and the Anxious Economy." American Economic Review 98, no. 4:1211-44.

Gârleanu, N., and L. H. Pedersen. Forthcoming. "Margin-Based Asset Pricing and Deviations from the Law of One Price." Review of Financial Studies.

Geanakoplos, J. 1997. "Promises, Promises." In The Economy as an Evolving Complex System II, ed. W. B. Arthur, S. N. Durlauf, and D. A. Lane, 285-320. Reading, MA: Addison-Wesley/Longman.

. 2003. "Liquidity, Default and Crashes: Endogenous Contracts in General Equilibrium." In Advances in Economics and Econometrics: Theory and Applications II, ed. M. Dewatripont, L. P. Hansen, and S. J. Turnovsky, 2:170-205. Cambridge: Cambridge University Press.

Gertler, M., and P. Karadi. 2009. "A Model of Unconventional Monetary Policy." Working paper, New York University. 
Gertler, M., and N. Kiyotaki. Forthcoming. "Financial Intermediation and Credit Policy in Business Cycle Analysis." In Handbook of Monetary Economics, vol. 3A, ed. B. M. Friedman and M. Woodford. Amsterdam: Elsevier.

Gorton, G., and A. Metrick. 2009a. "Haircuts." Working paper, Yale University. - 2009b. "Securitized Banking and the Run on Repo." Working paper, Yale University.

He, Z., and A. Krishnamurthy. 2008. "Intermediated Asset Prices." Working paper, Northwestern University.

$\rightarrow$ Hindy, A. 1995. "Viable Prices in Financial Markets with Solvency Constraints." Journal of Mathematical Economics 24, no. 2:105-35.

$\rightarrow$ Holmström, B., and J. Tirole. 1997. "Financial Intermediation, Loanable Funds, and the Real Sector." Quarterly Journal of Economics 112, no. 1:35-52.

$\rightarrow-1998$. "Private and Public Supply of Liquidity." Journal of Political Economy 106 , no. 1:1-39.

$\rightarrow \longrightarrow$. 2001. "LAPM: A Liquidity-Based Asset Pricing Model." Journal of Finance 56, no. 5:1837-67.

$\rightarrow$ Kiyotaki, N., and J. Moore. 1997. "Credit Cycles." Journal of Political Economy 105, no. 2:211-48.

- 2008. "Liquidity, Business Cycles and Monetary Policy." Working paper, Princeton University.

$\rightarrow$ Longstaff, F. 2004. "The Flight-to-Liquidity Premium in U.S. Treasury Bond Prices." Journal of Business 77, no. 3:511-26.

$\rightarrow$ Lorenzoni, G. 2008. "Inefficient Credit Booms." Review of Economic Studies 75, no. 3:809-33.

$\rightarrow$ Lustig, H., and S. Van Nieuwerburgh. 2005. "Housing Collateral, Consumption Insurance, and Risk Premia: An Empirical Perspective." Journal of Finance 60, no. 3:1167-1219.

$\rightarrow$ Mitchell, M., L. H. Pedersen, and T. Pulvino. 2007. "Slow Moving Capital." American Economic Review 97, no. 2:215-20.

Reis, R. 2009. "Interpreting the Unconventional U.S. Monetary Policy of 2007-09." Brookings Papers on Economic Activity, no. 2:119-82.

$\rightarrow$ Repullo, R., and J. Suarez. 2000. “Entrepreneurial Moral Hazard and Bank Monitoring: A Model of the Credit Channel." European Economic Review 44, no. 10:1931-50.

$\rightarrow$ Shleifer, A., and R. W. Vishny. 1992. "Liquidation Values and Debt Capacity: A Market Equilibrium Approach." Journal of Finance 47, no. 4:1343-66. 